\title{
The impact of size on particle drainage dynamics and antibody response
}

\author{
Simon Zinkhan ${ }^{\mathrm{a}, 1}$, Anete Ogrina ${ }^{\mathrm{b}, 1}$, Ina Balke ${ }^{\mathrm{b}}$, Gunta Reseviča ${ }^{\mathrm{b}}$, Andris Zeltins ${ }^{\mathrm{b}}$, \\ Simone de Brot ${ }^{c}$, Cyrill Lipp ${ }^{\mathrm{a}}$, Xinyue Chang ${ }^{\mathrm{a}}$, Lisha Zha ${ }^{\mathrm{d}}$, Monique Vogel ${ }^{\mathrm{a}}$, \\ Martin F. Bachmann ${ }^{a, e}$, Mona O. Mohsen ${ }^{a, f, "}$ \\ ${ }^{a}$ Department of BioMedical Research, University of Bern, Bern, Switzerland; Department of Immunology RIA, University Hospital Bern, Bern, Switzerland \\ ${ }^{\mathrm{b}}$ Latvian Biomedical Research \& Study Centre, Ratsupites iela 1, Riga, LV 1067, Latvia \\ ${ }^{\mathrm{c}}$ COMPATH, Institute of Animal Pathology, University of Bern, Bern, Switzerland \\ ${ }^{\mathrm{d}}$ International Immunology Center, Anhui Agricultural University, Hefei, Anhui, China \\ e Jenner Institute, Nuffield Department of Medicine, University of Oxford, UK \\ f Interim Translational Research Institute "iTRI", National Center for Cancer Care \& Research Doha, Qatar
}

\section{A R T I C L E I N F O}

\section{Keywords:}

Virus-like particles

Cowpea chlorotic mottle virus

Humoral immune response

\begin{abstract}
A B S T R A C T
Vaccine-induced immune response can be greatly enhanced by mimicking pathogen properties. The size and the repetitive geometric shape of virus-like particles (VLPs) influence their immunogenicity by facilitating drainage to secondary lymphoid organs and enhancing interaction with and activation of B cells and innate humoral immune components. VLPs derived from the plant Bromovirus genus, specifically cowpea chlorotic mottle virus (CCMV), are $T=3$ icosahedral particles. $(T)$ is the triangulation number that refers to the number and arrangements of the subunits (pentamers and hexamers) of the VLPs. CCMV-VLPs can be easily expressed in an E. coli host system and package ssRNA during the expression process. Recently, we have engineered CCMV-VLPs by incorporating the universal tetanus toxin (TT) epitope at the N-terminus. The modified CCMV $\mathrm{TT}_{\text {-VLPs suc- }}$ cessfully form icosahedral particles $T=3$, with a diameter of $\sim 30 \mathrm{~nm}$ analogous to the parental VLPs. Interestingly, incorporating TT epitope at the C-terminus of $\mathrm{CCMV}_{\mathrm{TT}}$-VLPs results in the formation of Rod-shaped VLPs, $\sim 1 \mu \mathrm{m}$ in length and $\sim 30 \mathrm{~nm}$ in width. In this study, we have investigated the draining kinetics and immunogenicity of both engineered forms (termed as Round-shaped CCMV $\mathrm{TT}^{-V_{L P S} \text { and Rod-shaped CCMV }} \mathrm{TT}^{-}$ VLPs) as potential B cell immunogens using different in vitro and in vivo assays. Our results reveal that Roundshaped $\mathrm{CCMV}_{\mathrm{TT}}$-VLPs are more efficient in draining to secondary lymphoid organs to charge professional

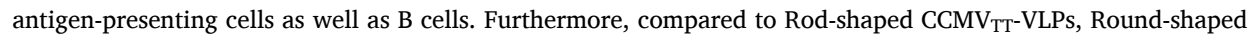
$\mathrm{CCMV}_{\mathrm{TT}}$-VLPs led to more than 100-fold increased systemic IgG and IgA responses accompanied by prominent formation of splenic germinal centers. Round-shaped $\mathrm{CCMV}_{\mathrm{TT}}$-VLPs could also polarize the induced $\mathrm{T}$ cell response toward Th1. To our knowledge, this is the first study investigating and comparing the draining kinetics and immunogenicity of one and the same VLP monomer forming nano-sized icosahedra or rods in the micrometer size.
\end{abstract}

\section{Introduction}

In 1956, Crick and Watson have stated that "it is a striking fact that almost all small viruses are rods or spheres", "These shells are constructed from a large number of identical protein molecules, of small or moderate size, packed together in a regular manner" [1]. The main reason for this arrangement is the small genome of viruses, especially RNA viruses. Many virus capsids are made up of multiple copies of a single coat protein (CP) arranged in an icosahedral or a helical-shaped geometry $[2,3]$. The icosahedral structure of viruses is more prevalent than the helical-shaped one.

Virus-like particles (VLPs) are one of the traditional vaccine platforms that emerged few decades ago and have made large strides in the field of vaccinology. The continuous interest in VLPs is due to several reasons including: being a safe platform as they lack replicating genetic materials, their immunogenicity which is largely due to antigen

\footnotetext{
* Corresponding author at: Department of BioMedical Research, University of Bern, Bern, Switzerland.

E-mail address: mona.mohsen@dbmr.unibe.ch (M.O. Mohsen).

1 Both authors contributed equally to this study.
} 
organization and repetitiveness viewed as potent pathogen-associated structural pattern (PASP) similar to pathogen-associated molecular patterns (PAMPs) [4-7], which are usually specific for pathogens, repetitive and rigid surfaces are also specific for pathogens, hence the term PASP. VLPs are further useful tools, as different epitopes may be displayed on their surface. In addition VLPs have favorable sizes ranging between 20 and $200 \mathrm{~nm}$ [4]. Such size allows VLPs to rapidly and efficiently filter and drain through the lymphatic system and gain access to lymphoid follicles [4,8-10]. The approved VLP-based vaccines currently in the market mostly exhibit an icosahedral surface geometry based on the quasi-equivalence concept described by Caspar and Klug in 1962 and expressed as Triangulation number (T) $[11,12]$. Triangulation refers to the number and arrangements of the subunits (pentamers and hexamers) of the coat protein of a virus or a VLP. It usually serves as a rough indicator of size. For example, human papilloma viruses (HPVs) are $T=7$ of $\sim 60 \mathrm{~nm}$ in size [13], while hepatitis E virus (HEV) VLPs are $T=1$ of $\sim 25 \mathrm{~nm}$ [14]. The different generations of hepatitis B virus (HBV) vaccines show highly organized sub-viral particles (SVPs) of $\sim 20-25 \mathrm{~nm}$ [15]. In addition, the arrangement of CPs of VLPs in helical or rod-shape geometry is also possible; tobacco-mosaic virus (TMV) is a well characterized representative of this category. Virions of TMV are $\sim 300 \mathrm{~nm}$ in length and $\sim 18 \mathrm{~nm}$ in width $[16,17]$. TMV-VLPs have been investigated as a promising platform in nanotechnology [18] and as a vaccine platform as well [19]. Nevertheless, knowledge is scarce regarding TMVVLPs drainage dynamics. Icosahedral VLPs can be manipulated by inserting few mutations to form rod-shaped VLP. For example, VLPs derived from the bacteriophage $\mathrm{Q} \beta$ can assemble in a rod-shaped particle following the mutation of five amino acid (a.a.) residues in the FG loop of its CP [20].

It is known that the repetitive surface geometry of icosahedral VLPs enhances optimal induction of B cell response via cross-linking of B cell receptors (BCRs) [21,22]. Previously, we have shown that displaying epitopes on icosahedral $T=3$ VLPs such as bacteriophage Q $\beta$ or plant-

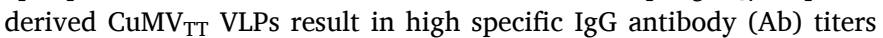
as well as neutralizing Abs [23-28]. Some studies have revealed that a vaccine based on rod-shaped tobacco-mosaic (TMV)-VLPs could also serve as an effective platform to display different epitopes capable of eliciting an immune response against different pathogens $[29,30]$.

Cowpea chlorotic mottle virus (CCMV) is a Bromovirus naturally infecting plants and therefore is non-infectious to humans. The infected plants develop yellow spots on their leaves, hence the name chlorotic [31]. The virus is an icosahedron $T=3$ of $\sim 28 \mathrm{~nm}$ in diameter, consisting of $180 \mathrm{CPs}$ of identical amino-acid sequence. The coat protein can adopt multiple quasi-equivalent forms referred to as the coat subunits $\mathrm{A}$, $\mathrm{B}$ and $\mathrm{C}$ forming either hexamers (alternating subunits $\mathrm{B}$ and $\mathrm{C}$ ) or pentamers (subunit A). The resulting virus particle consists of 12 pentamers and 20 hexamers [32]. Previously, it has been shown that icosahedral CCMV can be converted into rod-shaped particles after a disassembly/reassembly process [33].

In this study, we have demonstrated that CCMV-derived VLPs of different morphology (icosahedral or rod-shaped structure) can be obtained directly from recombinant $E$. coli cells. We specifically manipulated CCMV-VLPs by inserting the universal tetanus toxin (TT) epitope at the $\mathrm{C}$ or N-terminus to form icosahedral VLPs in the nanometer scale or rod-shaped VLPs with sizes in the micron range. Such intervention allowed us to study the impact of particle-size on drainage dynamics and magnitude of induced immune response using VLPs based on essentially the same VLP-monomer. Our results demonstrate for the first time that VLPs in the nm size range are vastly more immunogenic than micronsized particles.

\section{Materials and methods}

\subsection{Round-shaped and Rod-shaped $C C M V_{T T}$-VLPs cloning, expression and production}

Cloning of CCMV-CP with induced tetanus toxin epitope for expression: A cloned copy of the CCMV coat protein gene (wt $C P$ ) was obtained from Dr. Alain Tissot (Zürich) and used in PCR mutagenesis for insertion of the coding sequence of tetanus toxin epitope (TT830-843; QYIKANSFIGITE) in 5' - and $3^{\prime}$ - terminal ends of the CP gene. To replace the original amino acids at the N-terminus of CCMV CP with the TT epitope sequence, the pET42-CCMVwt plasmid was used as a template for PCR amplification and mutagenesis. NdeI site at the 5'end of the CCMVwt gene was used for cloning corresponding PCR products. To introduce the tetanus toxin epitope coding sequence into the CCMV-wt gene, two step PCR mutagenesis was necessary. For the first step amplification the following primers were used for $\mathrm{N}$ terminal PCR: CC_N83_d24F (5'ATACATATGGGCCAGTATATTAAGGCCAACTC CAAATTTATCGGGATTACCGA $3^{\prime}$ ) and CC_N83R (5' AGTTAAC TTCCCTGTACCGACTGTTTCGGTAATCCCGATAAATTTGGAGTTG 3').

For the second round the PCR products from the first round were diluted 1:50 and re-amplified with primers CC_N83_d24F and CC_AgeR (5' ACTTCGATACGCTGTAACCGGTCCA 3').

For $\mathrm{C}$ terminal insertion of TT epitope, the following primers were used: CC_C83F (5' TGACGACTCTTTCACTCCGGTCTATGGCCAGTATATTAAGGCCAACTCC $3^{\prime}$ ) and CC_C83R (5' TTACTCGAGAAGCTTATTACTCGGTAATCCCGATAAATTTGGAGTTG $3^{\prime}$ ). Second round of the PCR was performed as describe above using primers CC_C83R (5' TTACTCGAGAAGCTTATTACTCGGTAATCCCGATAAATTTGGAGTTG $3^{\prime}$ ) and CC_SacIIF (5' CCCTTGAACAACTCGCCGCGGA $3^{\prime}$ ).

The corresponding PCR fragments were analyzed in a $0.8 \%$ agarose gel and then purified using the GeneJet Gel Extraction kit (Thermo Fischer Scientific, Waltham, Massachusetts). Then the $5^{\prime}$ terminal end PCR product and plasmid pET42-CCMVwt were digested with enzymes NdeI and BshTI (Thermo Fischer Scientific, Waltham, Massachusetts) and ligated, resulting in plasmid pET42-CCMV-Ntt830. The 3'terminal end PCR product and plasmid pET42-CCMVwt were digested with enzymes Cfr42I and XhoI (Thermo Fischer Scientific, Waltham, Massachusetts) and ligated, resulting in plasmid pET42-CCMV-Ctt830.

E.coli XL1-Blue cells were used as a host for cloning and plasmid amplification. To avoid PCR errors several CP gene-containing pET42 plasmid clones were sequenced using the BigDye cycle sequencing kit and an ABI Prism 3100 Genetic analyser (Applied Biosystems, Foster City, California). After sequencing, the plasmid clones without sequence errors were chosen for further experiments.

Cloning of CCMV-SS-CP with induced tetanus toxin epitope for expression: To obtain "salt-stable" CCMV VLPs, the replacement of lysine against arginine in position 42 (K42R) was necessary. For CCMVwt-SS the following primers were used: CCP_salt_AgeI_R (5' TGTAACCGGTCCATGCTTTAATAGCGCGGCCTT 3') and CCM_NdeF (5' ATACATATGTCTACAGTCGGTACAGGG $3^{\prime}$ ). For CCMV-Ntt830-SS the following primers were used: CC_N83_d24F and CC_salt_AgeI_R. The corresponding PCR products were cloned into the pTZ57R/T vector (Thermo Fischer Scientific, Waltham, Massachusetts). E. coli XL1-Blue cells were used as a host for cloning and plasmid amplification. To avoid RT-PCR errors, several CP gene-containing pTZ57 plasmid clones were sequenced using the BigDye cycle sequencing kit and an ABI Prism 3100 Genetic analyser (Applied Biosystems, Foster City, California). After sequencing, corresponding DNA fragments without sequence errors were subcloned into the NdeI/AgeI sites of pET42-CCMVwt and pET42-CCMV-Ntt830 expression vectors, resulting in the expression plasmids pET42-CCMV-SS and pET42-CCMV-Ntt830-SS. For generating the $\mathrm{C}$ terminal tetanus toxin CCMV-SS construct the corresponding NdeI/ BsrGI-fragment from pET42-CCMV-SS was subcloned into pET-CCMVCtt830, generating the expression vector pET42-CCMV-Ctt830-SS. 
Expression and purification of CCMV-SS VLPs: To obtain all salt stable CCMV CP VLPs, each construct was transformed and expressed in E. coli C2566 cells (New England Biolabs, Ipswich, USA). After selection of clones with the highest expression levels of the target protein, E. coli cultures were grown in 2 XTY medium containing kanamycin $(25 \mathrm{mg} / \mathrm{l})$ on a rotary shaker (200 rev/min; Infors, Bottmingen, Switzerland) at $30{ }^{\circ} \mathrm{C}$ to an $\mathrm{OD} 600$ of $0.8-1.0$. Then, expression was induced with $0.2 \mathrm{mM}$ Isopropyl- $\beta$-D-thiogalactopyranoside (IPTG), and the medium was supplemented with $5 \mathrm{mM} \mathrm{MgCl}_{2}$ and $2 \mathrm{mM} \mathrm{CaCl}_{2}$. Incubation was continued on the rotary shaker at $20^{\circ} \mathrm{C}$ for $18 \mathrm{~h}$. The resulting biomass was collected by low-speed centrifugation and was frozen at $-70^{\circ} \mathrm{C}$. After thawing on ice, the cells were suspended in buffer containing 15 $\mathrm{mM}$ sodium phosphate $\mathrm{pH} 7.5$ supplemented with $150 \mathrm{mM} \mathrm{NaCl}$ (buffer A) with additional $0.5 \mathrm{mM}$ urea, $1 \mathrm{mM}$ PMSF, $5 \mathrm{mM}$ mercapto-ethanol, and were disrupted by ultrasonic treatment. Insoluble proteins and cell debris were removed by centrifugation $\left(13,000 \mathrm{rpm}, 30 \mathrm{~min}\right.$ at $\left.5{ }^{\circ} \mathrm{C}\right)$. All steps involved in the expression of VLP were monitored by SDS-PAGE using $12.5 \%$ gels.

CCMV-SS and CCMV-Ctt830-SS VLPs were separated from cellular proteins by ultracentrifugation (SW28 rotor, Beckman, Indianapolis, Indiana; at $25,000 \mathrm{rpm}, 6 \mathrm{~h}, 5^{\circ} \mathrm{C}$ ) in a sucrose gradient (20-60\% sucrose in buffer A, without mercapto-ethanol and urea, supplemented with $0.5 \%$ Triton $\mathrm{X}-100$ ). The content of gradient tubes was divided into six fractions, starting at the bottom of the gradient, and the fractions were analyzed by SDS-PAGE. Fractions containing CCMV-SS CP proteins were combined and dialyzed against 100 volumes of buffer A to remove the sucrose. If necessary, samples were concentrated using an Amicon Ultra15 centrifugal device (Millipore, Cork, Ireland).

However, soluble proteins of CCMV-Ntt830-SS were precipitated using a mixture of PEG 8,000 (8\%) and $\mathrm{NaCl}(0.15 \mathrm{M})$, collected by centrifugation and dissolved in buffer $\mathrm{A}$. $\mathrm{PEG} / \mathrm{NaCl}$ precipitation was repeated for CCMV-Ntt830-SS. After solubilisation or dialysis (in case of CCMV-SS), all CCMV CP preparations were purified two times using an ultracentrifuge and $30 \%$ sucrose cushion - first with additional $0.5 \%$ Triton X-100 and the second time without Triton X-100 (4 h, 50000 $\mathrm{rpm}, 4^{\circ} \mathrm{C}$; Type $70 \mathrm{Ti}$ rotor, Beckman, Indianapolis, Indiana) and the pellet was then dissolved in buffer A. If necessary, samples were concentrated using an Amicon Ultra-15 centrifugal device (Millipore, Cork, Ireland). To obtain pure preparations of CCMV-CPs for subsequent electron microscopy (EM) analysis, stability and immunological studies, the sucrose gradient, dialysis, and concentration steps were repeated.

All steps involved in the expression and purification of VLP were monitored by SDS-PAGE (using $12.5 \%$ gels). The concentration of purified CCMV-CPs were estimated using the QuBit fluorometer in accordance with manufacturer's recommendations (ThermoFisher Scientific, Waltham, Massachusetts). Concentrated VLP solutions were stored at $+4{ }^{\circ} \mathrm{C}$.

\subsection{Electron microscopy}

Purified Round-shaped or Rod-shaped CCMV $\mathrm{TT}_{\mathrm{T}}$-VLPs proteins (1 mg/ $\mathrm{ml}$ ) were adsorbed on carbon formvar-coated copper grids and were negatively stained with $0.5 \%$ uranyl acetate aqueous solution. The grids were examined using a JEM-1230 electron microscope (JEOL, Tokyo, Japan) at an accelerating voltage of $100 \mathrm{kV}$.

\subsection{Mass spectrometry}

Wild type $\mathrm{CCMV}_{\mathrm{TT}}$-VLPs, Round- or Rod-shaped CCMV $\mathrm{TT}$-VLPs (1 $\mathrm{mg} / \mathrm{ml}$ in buffer A) were diluted with a 2,5-Dihydroxyacetophenone (2,5-DHAPI) matrix solution and were spotted onto an MTP AnchorChip 400/384TF. Matrix assisted laser desorption/ionization (MALDI)-TOF MS analysis was carried out on an Autoflex MS (Bruker Scientific, Billerica, Massachusetts). The protein molecular mass (MM) calibration standard II (22.3-66.5 kDa; Bruker, Billerica, Massachusetts) was used for mass determination.

\subsection{SDS-Page and gel electrophoresis}

SDS-Page: $6 \mu \mathrm{g}$ of Round- or Rod-shaped $\mathrm{CCMV}_{\mathrm{TT}}$-VLPs were mixed with $2 \times$ mercaptoethanol and heated at $95^{\circ} \mathrm{C}$ for $3 \mathrm{~min}$ and then loaded into Any kD Mini-PROTEAN TGX precast protein gels (BIO-RAD, Hercules, California). Gel was run for $35 \mathrm{~min}$ at $180 \mathrm{~V}$. As reference Page Ruler ${ }^{\mathrm{TM}}$ Prestained Protein Ladder was used (Thermo Fisher Scientific, Waltham, Massachusetts). Gel electrophoresis: $10 \mu \mathrm{g}$ of Round- or Rodshaped $\mathrm{CCMV}_{\mathrm{TT}}$-VLPs were loaded on a $1 \%$ agarose gel. Nucleic acids were visualized using Cybr Safe DNA Gel Stain (Life Technologies, Carlsbad, California). $5 \mu$ l Quick-Load Purple $1 \mathrm{~kb}$ DNA ladder (New England Biolabs, Ipswich, Massachusetts) was used as reference. Gel was run for $30 \mathrm{~min}$ at $100 \mathrm{~V}$.

\subsection{Mice}

Wild type C57BL/6J mice were purchased from Harlan. All in vivo experiments were performed using 8-12 weeks old female mice. All animal procedures were conducted in accordance with the Swiss Animal Act (455.109.1 - September 2008, 5th).

\subsection{Vaccination regimen}

Wild type C57BL/6J mice (8-12 weeks, Harlan) were vaccinated subcutaneously (s.c.) with $15 \mu$ g Round- or Rod-shaped CCMV TT $_{\text {-VLPs in }}$ $100 \mu \mathrm{l}$ PBS on day 0 . Mice were boosted with an identical dose on day 14. Serum samples were collected on days $0,7,14,21,28$ and 35.

\subsection{The enzyme-linked immunosorbent assay (ELISA)}

For determination of total IgG antibody titers against Round- and Rod-shaped $\mathrm{CCMV}_{\mathrm{TT}}$-VLPs in sera of immunized mice, ELISA plates (Nunc Immuno MaxiSorp, Rochester, NY) were coated over night with Round- or Rod-shaped CCMV $\mathrm{TT}_{\mathrm{TT}}$-VLPs, respectively. Plates were washed with PBS-0.01\%Tween and blocked using $100 \mu \mathrm{l}$ PBS-Casein $0.15 \%$ for $2 \mathrm{~h}$. Sera from immunized mice were diluted $1 / 20$ initially and a $1 / 3$ dilution chain was performed. Plates were incubated for $1 \mathrm{~h}$ at $37^{\circ} \mathrm{C}$. After washing with PBS-0.01\%Tween, goat anti-mouse IgG conjugated to Horseradish Peroxidase (HRP) (Jackson ImmunoResearch, West Grove, Pennsylvania) was added $1 / 1000$ and incubated for $1 \mathrm{~h}$ at $37^{\circ} \mathrm{C}$. Plates were developed and OD 450 reading was performed.

IgG subclasses were measured from day 21 sera using the same ELISA protocol with the following secondary Abs: rat anti-mouse IgG1-HRP (BD Biosciences, San Jose, California) 1:1000, goat anti-mouse IgG2bHRP (Thermo Fischer Scientific, Waltham, Massachusetts) 1:1000, goat anti-mouse IgG2c-HRP (Southern Biotech, Birmingham, Alabama) 1:4000, rat anti-mouse IgG3-biotin (Becton, Dickinson, Franklin Lakes, New Jersey) 1:2000 followed by streptavidin-HRP (Dako, Glostrup, Denmark) 1:1000 incubated at $37^{\circ} \mathrm{C}$ for $1 \mathrm{~h}$.

IgA was measured using day 35 sera. IgG was depleted using Dynabeads ${ }^{\mathrm{TM}}$ Protein $\mathrm{G}$ (Thermo Fischer Scientific, Waltham, Massachusetts). Serum was diluted $1 / 20$ in PBS-Casein $0.15 \%$. $25 \mu$ l beads were used per sample. Manufacturer's protocol was followed until step 3. of "Bind Antibody". Supernatant was added to ELISA plates and a $1 / 3$ serial dilution was performed. For IgA detection, goat anti mouse IgA conjugated to HRP was used (Thermo Fisher Scientific, Waltham, Massachusetts) $1 / 4000$.

For OD50 calculations, if a sample did not reach the threshold a value of 1 was appointed.

\subsection{Measuring IFN- $\gamma$ in mouse serum}

Wild type C57BL/6J mice (8-12 weeks, Harlan) were vaccinated with $15 \mu \mathrm{g}$ Round or Rod-shaped $\mathrm{CCMV}_{\mathrm{TT}_{\mathrm{T}}}$-VLPs on day 0 and boosted on day 14. Serum from vaccinated mice was collected for measuring IFN- $\gamma$. ELISA MAX ${ }^{\mathrm{TM}}$ Deluxe Set Mouse IFN- $\gamma$ (Biolegend, San Diego, California) 
was performed according to manufacturer's instructions. Serum was used undiluted and concentration was interpolated to a standard curve of the sets standard sample.

\subsection{Trafficking of Round-and Rod-shaped $C C M V_{T T}-V L P s$ to draining lymph nodes}

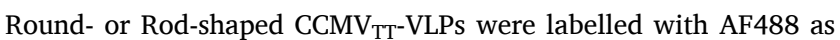
per manufacturer's instructions (Thermo Fischer Scientific, Waltham, Massachusetts) and stored at $-20{ }^{\circ} \mathrm{C}$. Wild type C57BL/6J mice (8-12 weeks, Harlan) were injected with $10 \mu \mathrm{g}$ of the VLPs in the footpad under isoflurane anesthesia. Popliteal LNs were collected $3 \mathrm{~h}$ and $24 \mathrm{~h}$ following footpad injection. Lymph nodes were treated with collagenase D (Roche, Basel, Switzerland) and DNase I (Boehringer, Ingelheim am Rhein, Germany) in DMEM medium containing 5\% FBS and 1\% Strep/ Penicillin for $30 \mathrm{~min}$ at $37{ }^{\circ} \mathrm{C}$. Lymph nodes were smashed using $70 \mu \mathrm{m}$ cell strainers, RBCs were lysed with ACK buffer. Cells were stained with Fc block CD16/CD32 (FRC/4G8) and then with 7-AAD viability staining solution (Thermo Fisher Scientific, Waltham, Massachusetts) 1/500, anti-CD8 PE clone 53-6.7 (BD Biosciences, San Jose, California), antiCD11c APC clone HL3 (BD Biosciences, San Jose, California), antiCD11b PE-Cy7 clone M1/70 (Thermo Fisher Scientific, Waltham, Massachusetts), anti-F4/80 PE clone BM8 (Thermo Fisher Scientific, Waltham, Massachusetts), anti-CD19 APC-H7 clone 1D3 (BD Biosciences, San Jose, California), anti-CD45R/B220 PE-Cy7 clone RA3-6B2 and MHC-II PE clone M5/114.15.2 (Thermo Fisher Scientific, Waltham, Massachusetts) in different mixtures (gating strategy shown in Supplementary Fig. 1). Fluorescence labelled cells were recorded using a BD FACSCanto $^{\text {TM }}$ Flow Cytometer (BD Biosciences, San Jose, California).

\subsection{Immunofluorescence}

Round- or Rod-shaped $\mathrm{CCMV}_{\text {TT }}$-VLPs were labelled with AF488 as per manufacturer's instructions (Thermo Fischer Scientific, Waltham, Massachusetts) and stored at $-20{ }^{\circ} \mathrm{C}$. Wild type C57BL/6J mice (8-12 weeks, Harlan) were injected with $10 \mu \mathrm{g}$ of the VLPs in the footpad under isoflurane anesthesia. Popliteal LNs were collected $3 \mathrm{~h}$ and $24 \mathrm{~h}$ following footpad injection and embedded in Tissue-Tek optimum cutting temperature compound (Sakura, Torrance, California) without prior fixation. Cryostat sections (7 $\mu \mathrm{m}$ in thickness) on Superforst/Plus glass slides (Thermo Fischer Scientific, Waltham, Massachusetts) were air-dried overnight and then fixed for $10 \mathrm{~min}$ in ice-cold $100 \%$ acetone (PanReac, Barcelona, Spain). After rehydration (5 min in $1 \times \mathrm{PBS}$ ), sections were blocked with $1 \%(w / v)$ BSA (Sigma Aldrich, St. Louis, Missouri) and $1 \%(v / v)$ normal mouse serum. Immunofluorescence labeling was done with Abs diluted in PBS containing $0.1 \%(\mathrm{w} / \mathrm{v})$ BSA and $1 \%(\mathrm{v} / \mathrm{v})$ normal mouse serum. Sections were washed 3 times for $5 \mathrm{~min}$ in $1 \times$ PBS after every labeling step. LN staining: macrophages were detected using a primary antibody against CD11b $(1 / 1000$, rat anti mouse CD11b conjugated with PE; BD Biosciences, San Jose, California), B cell follicles were identified using rat anti mouse CD45/B220 Alexa F647 (1/1000; BD Biosciences, San Jose, California). Images were acquired on an Axioplan microscope using an AxioCam MRn (Zeiss).

\subsection{Histology of lymph node}

Round- or Rod-shaped $\mathrm{CCMV}_{\mathrm{TT}}$-VLPs were labelled with AF488 as per manufacturer's instructions (Thermo Fischer Scientific, Waltham, Massachusetts) and stored at -20 . Wild type C57BL/6J mice (8-12 weeks, Harlan) were injected with $10 \mu \mathrm{g}$ of the VLPs in the footpad under isoflurane anesthesia. Popliteal LNs were collected $3 \mathrm{~h}$ and $24 \mathrm{~h}$ following footpad injection and fixed with $4 \%$ paraformaldehyde solution (Sigma Aldrich, St. Louis, Missouri). Of each group, two to four murine popliteal LNs were histologically examined by a board-certified veterinary pathologist (SdB). Of each $\mathrm{LN}$, a full cross section, stained with Hematoxylin and Eosin (HE), was assessed for any histopathological changes.

\subsection{Statistical analysis}

Data were analyzed and presented as mean \pm SEM using GraphPad PRISM 8. Comparison between the groups was performed using the Mann-Whitney test. $p$-values are given as exact values.

\section{Results}

3.1. Directional insertion of tetanus toxin (TT) epitope in the $N$ or $C$ terminus results in Round- or Rod-shaped CCMV $V_{T T}$-VLPS

In a first step, we engineered CCMV-VLPs derived from a non-human pathogenic plant virus by incorporating a powerful $\mathrm{T}$ cell stimulatory epitope derived from tetanus toxin (TT) (830-843) at the N or C-terminus of CCMV-VLPs. The TT epitope was genetically fused to the capsid protein (CP) of CCMV-VLPs as has been previously described for our newly developed platform derived from cucumber-mosaic virus-like

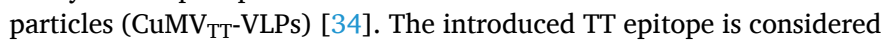
a universal epitope in humans as it is recognized by essentially all individuals. Since all individuals have been immunized against TT, memory Th cells may be able to help B cells to generate protective IgG even under more challenging conditions such as in aged populations [34]. CCMV-VLPs with insertion of TT epitope at the N-terminus retain their self-assembly as an icosahedron similar to the native virus. In contrast, insertion of TT epitope at the C-terminal end led to formation of Rod-shaped particles. Both Round- and Rod-shaped CCMV-VLPs forms carry a lysine to arginine mutation at residue 42 [35]. This mutation renders the VLPs less sensitive to $\mathrm{pH}$ and salt concentration (Ogrina, Balke, Zeltins; unpublished), which is an advantage in in vivo environments. Therefore, the engineered VLPs in this study are saltstable (SS). The shape and integrity of the cloned VLPs were confirmed via electron microscopy which shows a size of $\sim 30 \mathrm{~nm}$ in diameter for CCMV-Ntt-SS (Fig. 1a). The size of the CCMV $\mathrm{TT}-\mathrm{Ctt}-\mathrm{SS}$ greatly varies in length but can reach up to more than $1 \mu \mathrm{m}$, with a width of about $30 \mathrm{~nm}$. Fig. $1 \mathrm{~b}$ shows a magnified image of $\mathrm{CCMV}_{\mathrm{TT}}$-Ctt-SS VLPs for easy comparison of their width with the icosahedral CCMV $\mathrm{TT}_{\mathrm{TT}}$-Ntt-SS VLPs in Fig. 1a. To reach a rather homogenous population, we performed sucrose gradient separation to focus on the long rods (Fig. 1c). For simplification we refer to the two forms of engineered $\mathrm{CCMV}_{\mathrm{TT}}$ in this paper as Round-shaped $\mathrm{CCMV}_{\mathrm{TT}}$-VLPs (CCMV-Ntt-SS) and Rodshaped CCMV $\mathrm{TT}_{\mathrm{TT}}$-VLPs (CCMV-Ctt-SS).

To further characterize the two forms of $\mathrm{CCMV}_{\mathrm{TT}}$, we performed mass spectrometry (MS). MS data revealed a molecular weight for the CP monomers of Round- and Rod-shaped CCMV $\mathrm{TT}_{\text {TT }}$-VLPs of roughly 21.8 and $21.9 \mathrm{kDa}$, respectively (Fig. 1d). The original CCMV-SS (salt-stable CCMV without TT insertion) is formed by CPs of roughly $20.2 \mathrm{kDa}$. Considering the weight of the TT $830-843$ epitope of $1.611 \mathrm{kDa}$ the obtained data are consistent with a fusion of the CCMV-SS CP to this epitope. Reducing SDS-page experiments confirmed these findings and showed bands for Round- and Rod-shaped $\mathrm{CCMV}_{\mathrm{TT}^{-}}$-VLPs of equal height at the appropriate position (Fig. 1e).

Both engineered $\mathrm{CCMV}_{\mathrm{TT}}$-VLPs were produced in an E. coli system. The VLPs packaged ssRNA derived from $E$. coli spontaneously, which serves as a potent TLR7/8 ligand. The concentration of RNA in both Round- and Rod-shaped CCMV $\mathrm{TT}_{\mathrm{T}}$-VLPs was similar when measured at $260 \mathrm{~nm}$. The RNA content of the Round-shaped $\mathrm{CCMV}_{\mathrm{TT}}$-VLPs could also be visualized by agarose gel electrophoresis, however this was less efficient for the Rod-shaped $\mathrm{CCMV}_{\mathrm{TT}}$-VLPs due to its large size which do not allow the particles to migrate through the gel. The agarose gel was also stained with Coomassie blue, staining the protein shell of VLPs (Fig. 1f and Supplementary Fig. 2). 
a. Round-shaped CCMV $\mathrm{TT}_{\mathrm{T}}$ VLPS

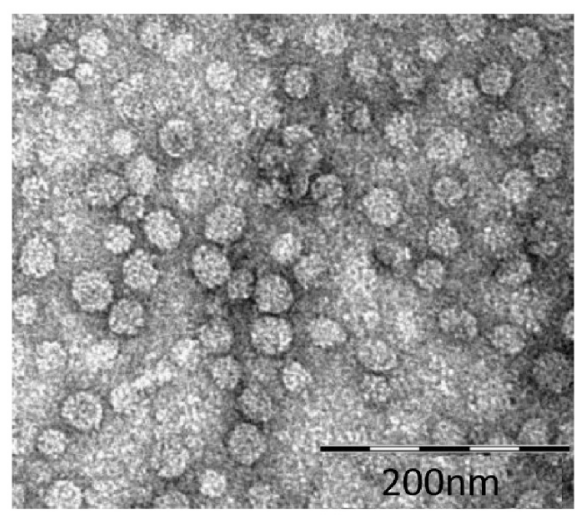

b. Rod-shaped CCMV $\mathrm{TT}_{\mathrm{T}} \mathrm{VLPs}$

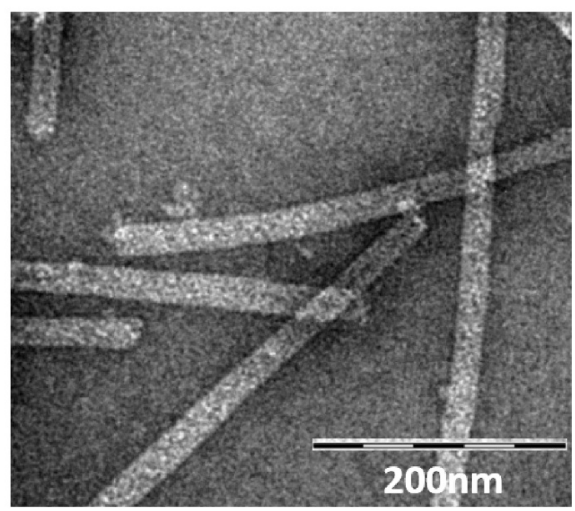

c.

Rod-shaped $\mathrm{CCMV}_{\mathrm{TT}}$-VLPs

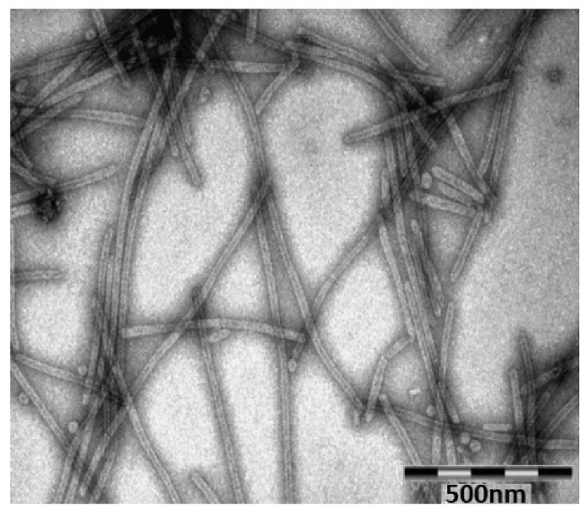

d.

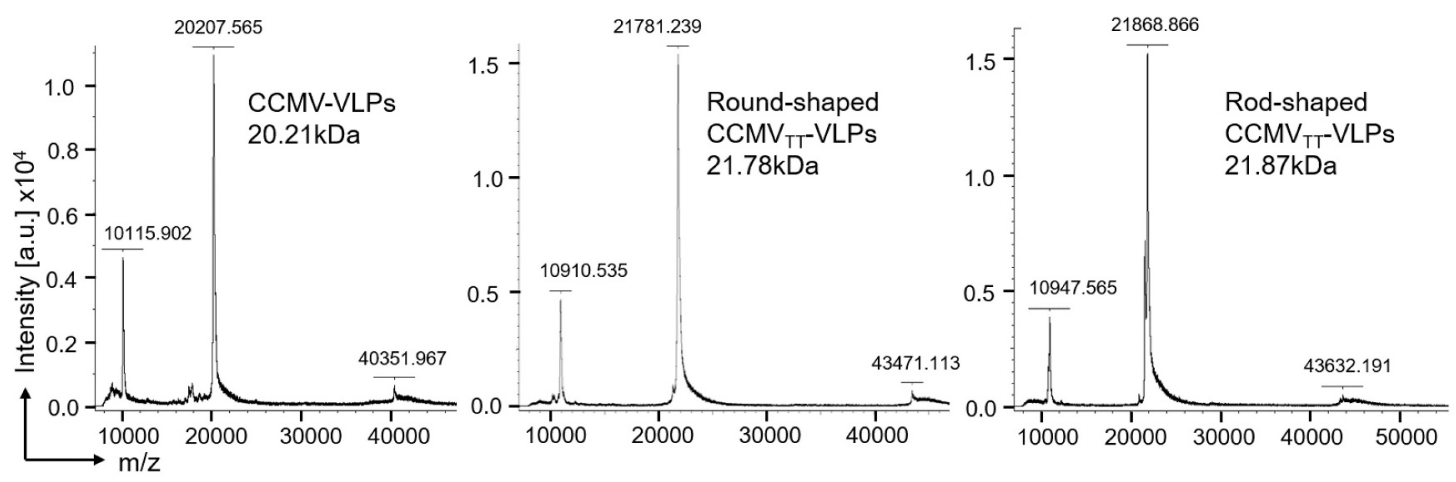

e.

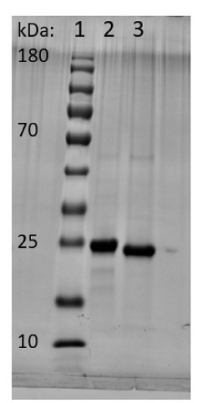

f.

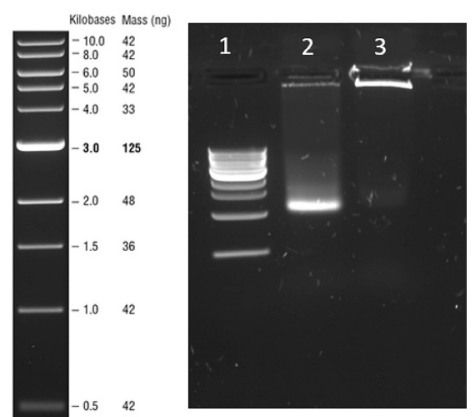

Lane Details:

1. DNA Ladder

2. Round- shaped $\mathrm{CCMV}_{\mathrm{TT}}$-VLPs

3. Rod-shaped $\mathrm{CCMV}_{T T^{-}}$ VLPs

Fig. 1. Directional insertion of tetanus toxin (TT) epitope in the $N$ or C-terminus results in Round- or Rod-shaped CCMV $V_{T T}$-VLPs. a, EM of Round-shaped and b./c. Rodshaped $\mathrm{CCMV}_{\mathrm{TT}}$-VLPs, adsorbed on carbon grids and negatively stained with uranyl acetate solution, scale bars $200 \mathrm{~nm}$ (Round) and $200 \mathrm{~nm} / 500 \mathrm{~nm}$ (Rod). Round-shaped $\mathrm{CCMV}_{\mathrm{TT}}$-VLPs are $\sim 30 \mathrm{~nm}$ in diameter, Rod-shaped $\mathrm{CCMV}_{\mathrm{TT}}-\mathrm{VLPs}$ are $\sim 1 \mu \mathrm{m}$ in length and $\sim 30 \mathrm{~nm}$ in width. $d$, Mass spectrometry data, from left to right: wild type CCMV-VLPs, Round-shaped $C_{C M V}$ TT $-V L P s$ and Rod-shaped $C_{C M V}$ TT $-V L P s . ~ e$, Reducing SDS-Page stained with Coomassie-blue stain, lane 1: protein marker, lane 2: Round-shaped $\mathrm{CCMV}_{\mathrm{TT}}$-VLPs, lane 3: Rod-shaped $\mathrm{CCMV}_{\mathrm{TT}}$-VLPs. $f$, Agarose gel stained with SYBR safe, lane 1: DNA ladder, lane 2: Round-shaped $\mathrm{CCMV}_{\mathrm{TT}} \mathrm{VLPs}$, lane 3: Rod-shaped $\mathrm{CCMV}_{\mathrm{TT}}$-VLPs. (For interpretation of the references to color in this figure legend, the reader is referred to the web version of this article.)

3.2. Round-shaped $C C M V_{T T}$-VLPs exhibit faster draining kinetics and interaction with cells in draining lymph nodes compared to Rod-shaped $C C M V_{T T}-V L P S$

To test the role of size in lymphatic trafficking of the engineered VLPs, we assessed and visualized the accumulation and interaction of Round- or Rod-shaped $\mathrm{CCMV}_{\mathrm{TT}}$-VLPs in murine popliteal lymph nodes (LNs) $3 \mathrm{~h}$ and $24 \mathrm{~h}$ after injection in mouse footpads. To this end, Roundand Rod-shaped CCMV $\mathrm{TT}_{\mathrm{T}}$-VLPs were labelled with AF488 and $10 \mu \mathrm{g}$ of either VLPs were injected s.c. in the mouse footpad. The popliteal LN in each group was collected $3 \mathrm{~h}$ or $24 \mathrm{~h}$ following injection and processed as explained in the method section. We have studied the following cells for their ability to interact with $\mathrm{CCMV}_{\mathrm{TT}}$-VLPs: lymphoid-derived dendritic cells (DCs) characterized by $\mathrm{CD}^{+} \mathrm{CD} 11 \mathrm{c}^{+}$, conventional DCs (cDCs) characterized by $\mathrm{CD} 8^{-} \mathrm{CD} 11 \mathrm{c}^{+}$, macrophage-derived cells characterized by $\mathrm{CD} 11 \mathrm{~b}^{+}$and macrophages characterized by $\mathrm{CD} 11 \mathrm{~b}^{+} \mathrm{F} 4 / 80^{+}$ as well as B cells identified by $\mathrm{CD} 19^{+}$or more generally by CD45R/ $\mathrm{B}_{22}{ }^{+}$. Lymphoid-derived DCs or cDCs (Fig. 2a and b) did not show a significant increase in the interaction with Round- compared to Rodshaped $\mathrm{CCMV}_{\mathrm{TT}}-\mathrm{VLPs}$ at $3 \mathrm{~h}$. However, macrophages $\mathrm{CD} 11 \mathrm{~b}^{+} \mathrm{F} 4 / 80^{+}$ (Fig. 2c), macrophage-derived cells CD11 $\mathrm{b}^{+}$(Fig. 2d and h-top) as well as B cells $\mathrm{CD} 19^{+}$(Fig. 2.e, f and h-middle) or CD45R/B220 (Fig. 2.g and h-bottom) were more efficient in interacting with Round-shaped $\mathrm{CCMV}_{\mathrm{TT}}$-VLPs than with the Rod-shaped ones at $3 \mathrm{~h}$. Such findings confirm previous studies highlighting the ability of nanoparticles ranging from 20 to $200 \mathrm{~nm}$ to directly drain to the LNs $[36,37]$. 

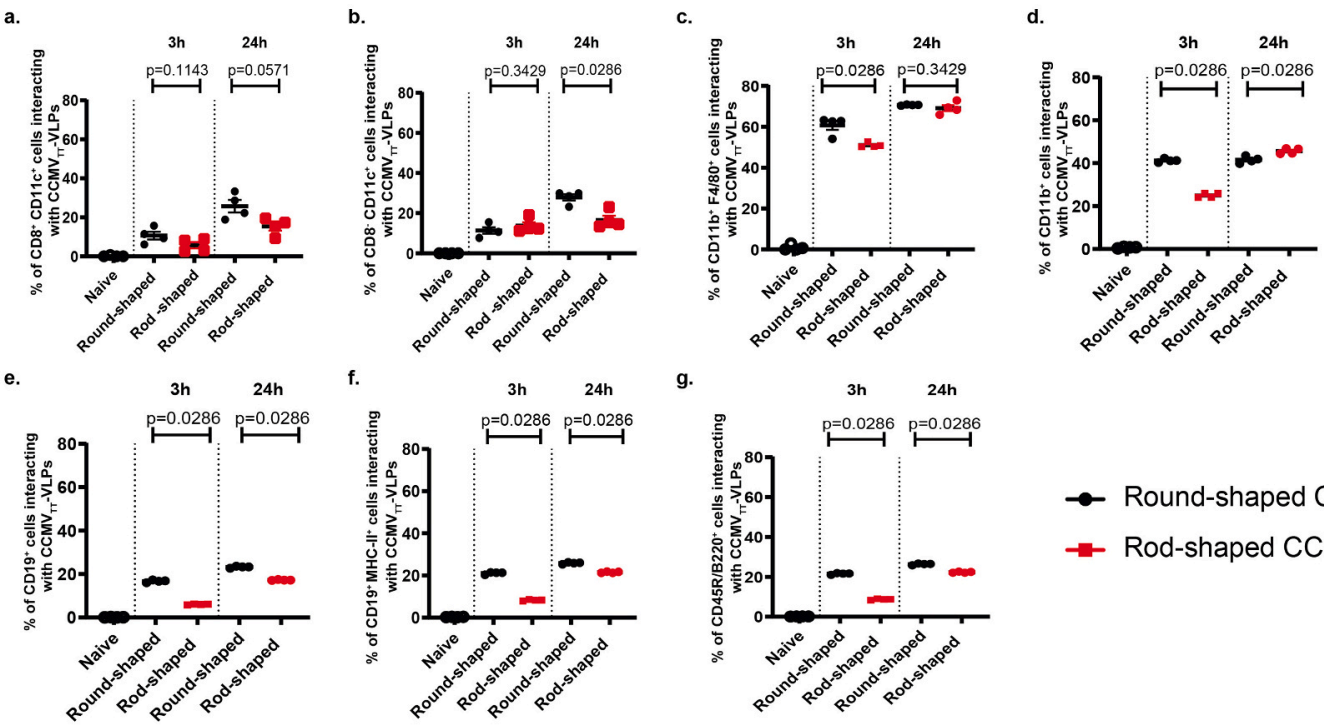

g.

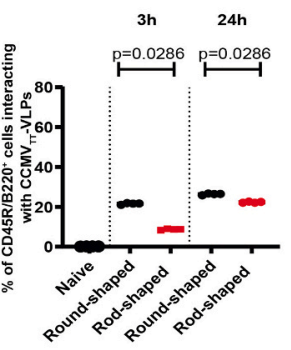

$\rightarrow$ Round-shaped CCMV TT-VLPs

- Rod-shaped CCMV ${ }_{T}$-VLPs
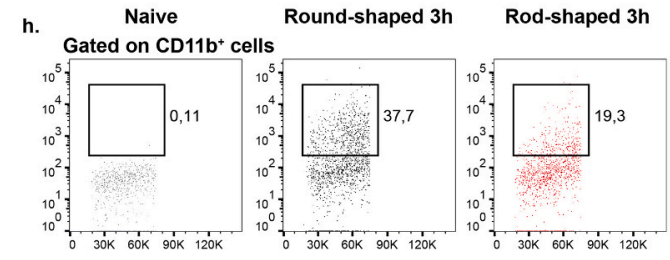

Gated on CD19+
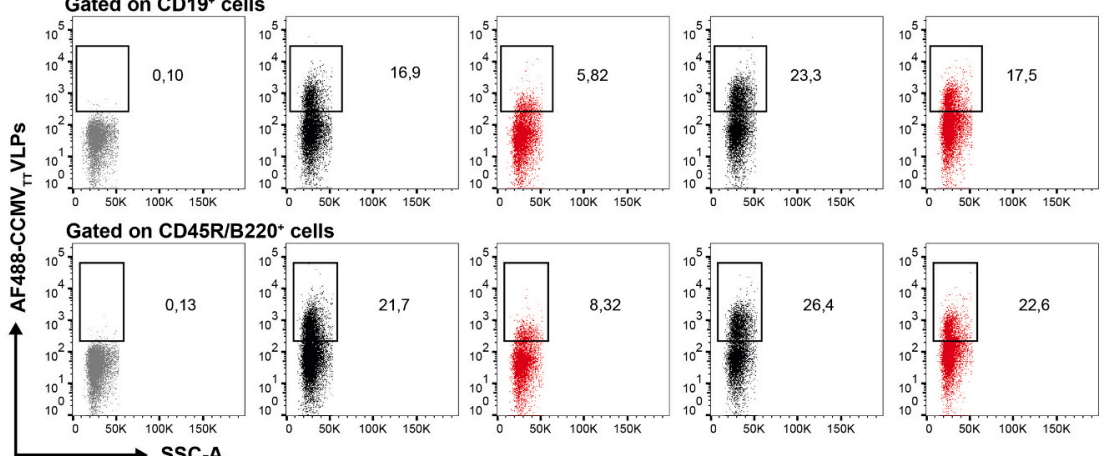

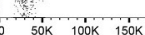

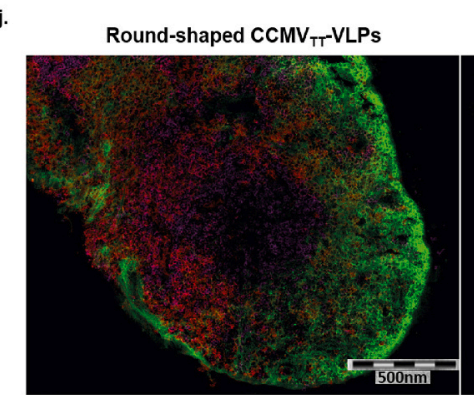

Rod-shaped $\mathrm{CCMV}_{\mathrm{TT}^{-}}$-VLPS
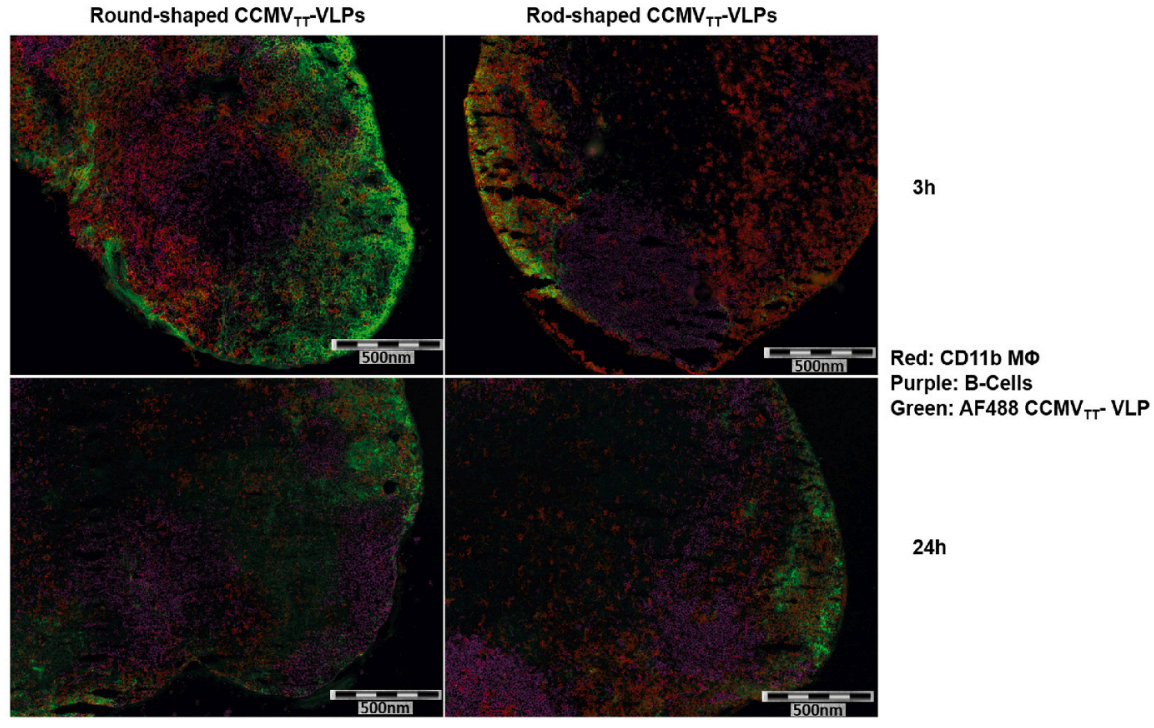

(caption on next page) 


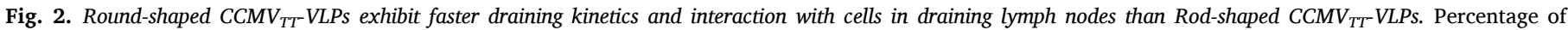

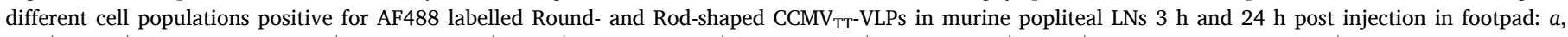

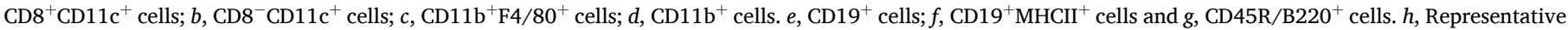

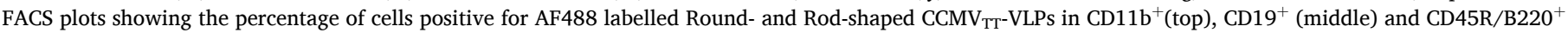

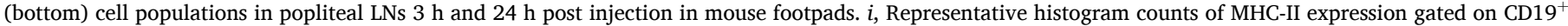

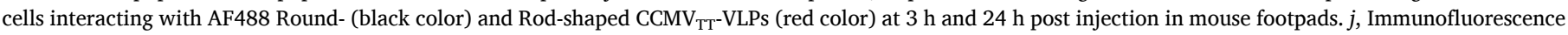

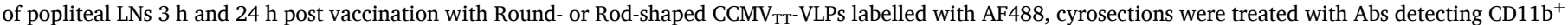

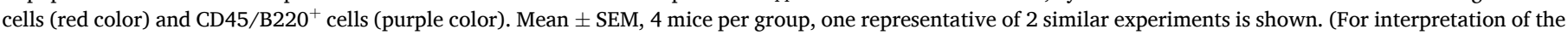
references to color in this figure legend, the reader is referred to the web version of this article.)

Nevertheless, the Rod-shaped $\mathrm{CCMV}_{\mathrm{TT}}$-VLPs were also detectable in the popliteal draining LN $3 \mathrm{~h}$ post injection in the footpad, despite their micron-size. This could be due to the fact that the width of these rods is $\sim 30 \mathrm{~nm}$, similar to the diameter of the Round-shaped $\mathrm{CCMV}_{\mathrm{TT}}$-VLPs enabling their draining through the lymphatic vessels. Twenty-four hours following the injection in the footpad, there was no significant difference in the interaction between Round- or Rod-shaped $\mathrm{CCMV}_{\mathrm{TT}^{-}}$ VLPs with cDCs or macrophages. However, other subsets of macrophage-derived cells characterized by $\mathrm{CD} 11 \mathrm{~b}^{+}$were more efficient in interacting with Rod-shaped $\mathrm{CCMV}_{\mathrm{TT}}$-VLPs, further studies are required to characterize these subsets. $B$ cells still showed a significantly increased interaction with the Round-shaped $\mathrm{CCMV}_{\mathrm{TT}}$-VLPs compared to the Rod-shaped ones. $\mathrm{CD} 19^{+} \mathrm{B}$ cells interacting with Round-shaped $\mathrm{CCMV}_{\mathrm{TT}}$-VLPs showed a higher expression of MHC-II at 3 and $24 \mathrm{~h}$ (Fig. 2i). Additionally, we have calculated the percentage of $\mathrm{CD} 11 \mathrm{c}^{+}$, $\mathrm{CD}_{11 \mathrm{~b}}{ }^{+} \mathrm{F} 4 / 80^{+}, \mathrm{CD} 11 \mathrm{~b}^{+}$and $\mathrm{CD} 19^{+}$cell populations in the pool of total cells interacting with AF488 Round- or Rod-shaped CCMV $\mathrm{TT}$-VLPs in the popliteal LN $3 \mathrm{~h}$ after injection in the mouse footpad. The $\mathrm{CD} 19^{+} \mathrm{B}$ cell

a.
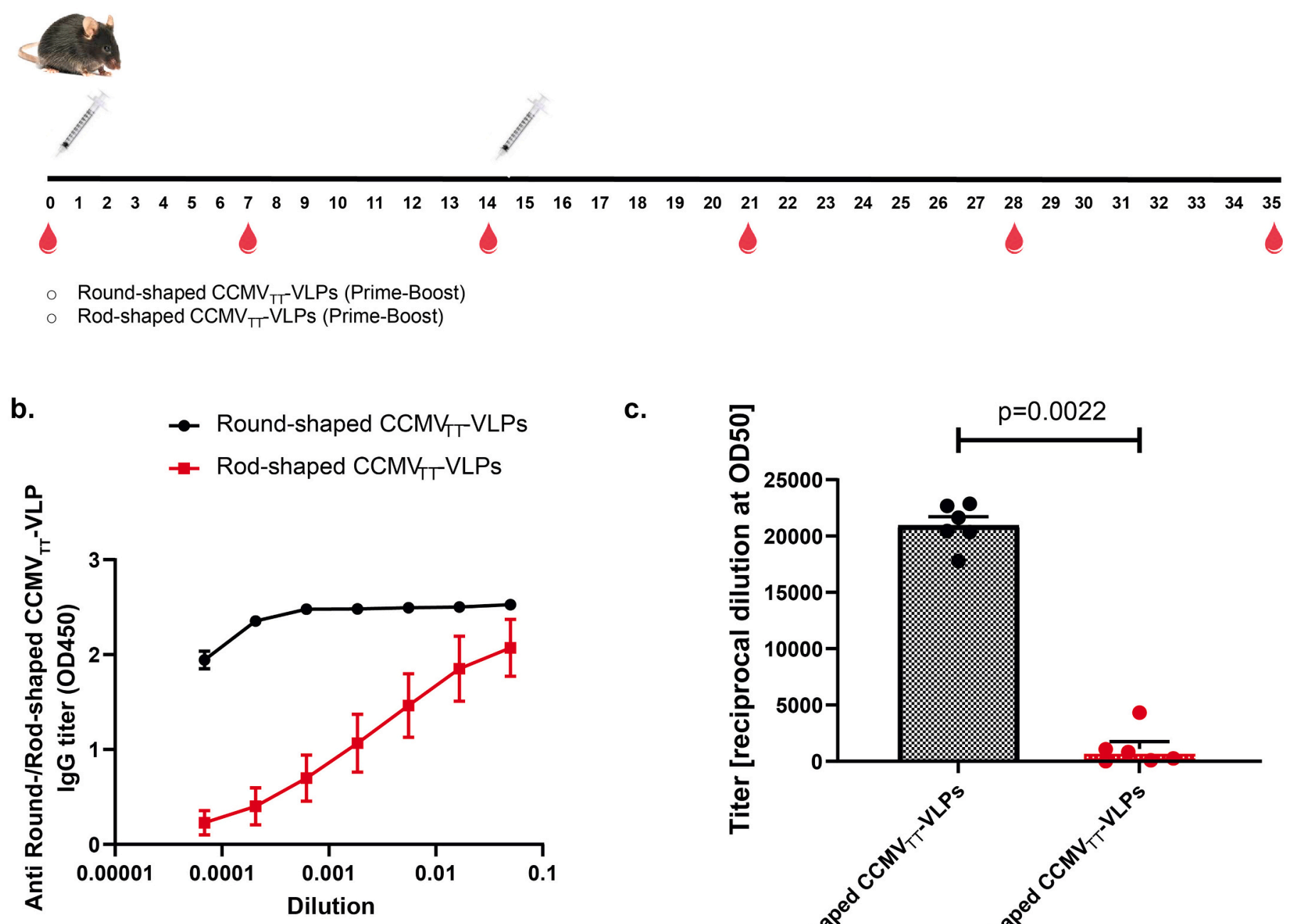

c.

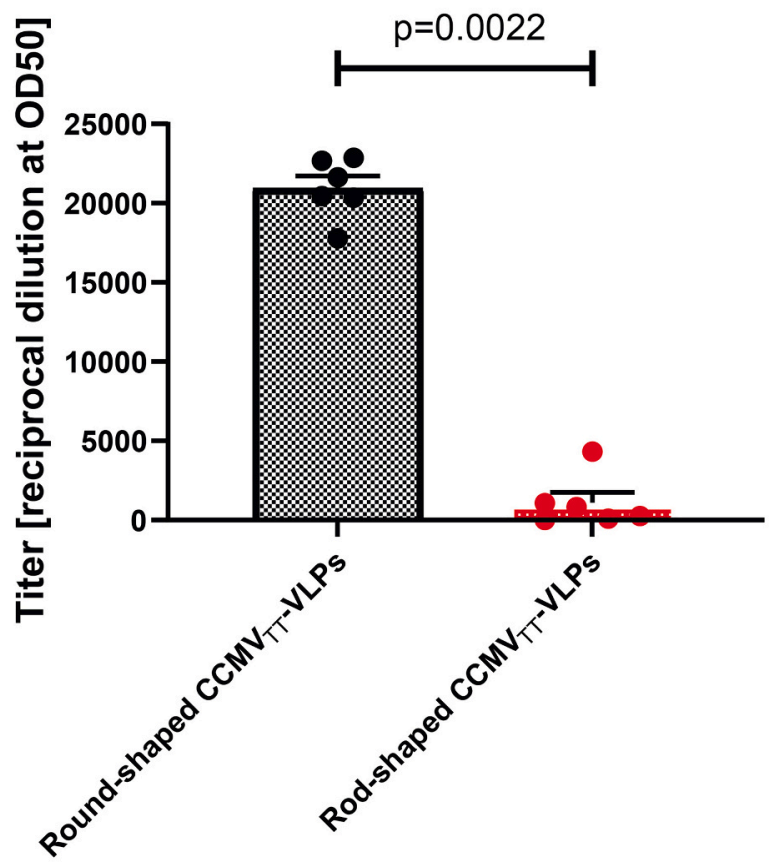

Fig. 3. Round-shaped $C C M V_{T T}$-VLPs are more potent at inducing IgG antibodies than Rod-shaped $C C M V_{T T}-V L P s$. $a$, Vaccination regimen and bleeding time-points. $b$, IgG titer of Round- and Rod-shaped CCMV $\mathrm{TT}_{\mathrm{T}} \mathrm{VLP}$ immunized mice measured in day 21 mice sera using OD450nm. ELISA plates were coated with Round-shaped CCMV TT- $^{-}$

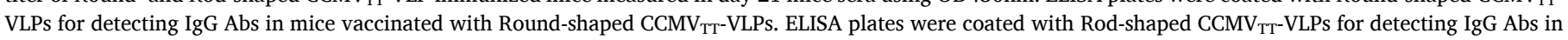

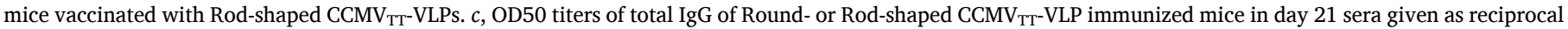
dilution values of data depicted. Mean \pm SEM, 6 mice per group, one representative of 2 similar experiments is shown. 
population contributes most to this pool (Supplementary Fig. 3).

We next followed the arrival of the labelled $\mathrm{CCMV}_{\mathrm{TT}}$-VLPs to the draining LNs by fluorescence microscopy of cryosections obtained from excised popliteal LNs at $3 \mathrm{~h}$ and $24 \mathrm{~h}$ following injection in the mouse footpad. The sections were co-stained with macrophage-derived cells and $\mathrm{B}$ cell markers, $\mathrm{CD} 11 \mathrm{~b}^{+}$and $\mathrm{CD} 45 / \mathrm{B} 220^{+}$, respectively. The results demonstrate that AF488 Round-shaped $\mathrm{CCMV}_{\mathrm{TT}}$-VLPs accumulated in large numbers in the subcapsular sinus area (SCS), the cortex and the medullary sinus (MS) of the popliteal LNs $3 \mathrm{~h}$ post injection (Fig. 2j). $\mathrm{CD}_{11} \mathrm{~b}^{+}$cells were prominent $3 \mathrm{~h}$ following injection with Roundshaped $\mathrm{CCMV}_{\mathrm{TT}}$-VLPs at the SCS and MS. Rod-shaped $\mathrm{CCMV}_{\mathrm{TT}}$-VLPs were less visible in the popliteal LN $3 \mathrm{~h}$ post injection in the footpad and their presence was confined to the SCS with scarce VLPs in the cortex. Twenty-four hours post injection, Round-shaped $\mathrm{CCMV}_{\mathrm{TT}}$-VLPs were found deeper in the popliteal LN. Whereas, this observation was less

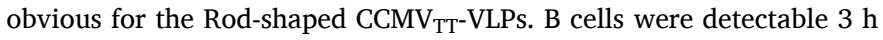
and $24 \mathrm{~h}$ post injection of the VLPs in the mouse footpads. As the accumulation of Round-shaped $\mathrm{CCMV}_{\text {TT }}$-VLPs was prominent $3 \mathrm{~h}$ post injection in the footpad, the B cell signal was less noticeable. Twentyfour hours later the accumulation of B cells was pronounced at the SCS and the cortical area of the LN upon injection of both types of $\mathrm{CCMV}_{\mathrm{TT}}$-VLPs.

\subsection{Round-shaped $C C M V_{T T}$-VLPs are more potent at inducing IgG antibodies than Rod-shaped $C C M V_{T T}-V L P S$}

In a next step, we have assessed the humoral immune response induced by both engineered Round- and Rod-shaped CCMV $\mathrm{TT}_{\mathrm{TT}}$-VLPs. It is important to keep in mind that it is usually difficult to compare different sized particles for their immunogenicity as for spheres, the surface is proportional to radius $(r)^{2}$, while the weight will be proportional to $(r)^{3}$. Hence the weight of the injected particles grows much more rapidly than the surface, rendering a comparison difficult. In contrast, for rods, both the surface and weight are proportional to the length of the rod, rendering this comparison more appropriate.

Hence, C57BL/6J mice were vaccinated subcutaneously (s.c.) with $15 \mu \mathrm{g}$ of Round- or Rod-shaped CCMV $\mathrm{TT}_{\mathrm{TL}}$-VLs on day 0 and boosted once on day 14 as illustrated in Fig. 3a. Serum was collected on day 0 before vaccination and subsequently on days 7, 14, 21, 28 and 35. Total specific IgG response against Round- or Rod-shaped CCMV $\mathrm{TT}_{\mathrm{T}}$-VLPs was assessed by ELISA. The Round-shaped $\mathrm{CCMV}_{\mathrm{TT}}$-VLPs were very potent at inducing specific IgG responses 7 days following the administration of the first dose. These responses were enhanced dramatically on days 14, 21, 28 and 35. On the contrary, vaccination with Rod-shaped $\mathrm{CCMV}_{\mathrm{TT}^{-}}$ VLPs led to low specific IgG titers after the first dose which have been increasing significantly only following boost on day 14 (Supplementary Fig. 4a and b). However, even following the boost specific IgG titers remained higher for Round-shaped $\mathrm{CCMV}_{\mathrm{TT}}$-VLP immunized mice, as shown for day 21 serum in Fig. $3 \mathrm{~b}$ and c.

Even though subunits of both VLPs were almost identical, in order to test the cross-reactivity of both Round- and Rod-shaped CCMV $\mathrm{TT}_{\mathrm{TT}} \mathrm{VLPs}$, we have tested the collected sera in ELISA coated with the opposite VLP shape. Specifically, sera from mice vaccinated with Round-shaped $\mathrm{CCMV}_{\mathrm{TT}}$-VLPs were tested by ELISA on plates coated with Rod-shaped $\mathrm{CCMV}_{\mathrm{TT}}$-VLPs and vice versa. Our results showed that sera from mice vaccinated with Round-shaped $\mathrm{CCMV}_{\mathrm{TT}}$-VLPs are capable of recognizing the Rod-shaped $\mathrm{CCMV}_{\mathrm{TT}}$-VLPs after a single dose on day 7. The response was enhanced on days 14, 21, 28 and 35. However, sera from mice vaccinated with Rod-shaped $\mathrm{CCMV}_{\mathrm{TT}}$-VLPs could only significantly recognize the Round-shaped $\mathrm{CCMV}_{\mathrm{TT}}$-VLPs after boosting (Supplementary Fig. $4 \mathrm{c}$ and d). This indicates the same epitope(s) to be responsible for induction of humoral immune responses in both constructs, despite of different assembly of coat proteins and possible small differences in secondary/tertiary structure. In a next step, we have produced Rodshaped $\mathrm{CCMV}_{\mathrm{TT}}$-VLPs exhibiting variation in lengths including smaller fragmented pieces of less than $\sim 1 \mu \mathrm{m}$ in length (By ways of using polyethylene glycol precipitation instead of sucrose gradient centrifugation for purification, as described for Round-shaped $\mathrm{CCMV}_{\mathrm{TT}}$-VLPs in the methods section; Supplementary Fig. 5a). The results showed that specific anti-IgG response against the Rod-shaped $\mathrm{CCMV}_{\mathrm{TT}}$-VLPs was enhanced substantially, indicating that indeed the rod-length limited the magnitude of the immune response (Supplementary Fig. 6a). In all other experiments presented in this paper the more homogeneous $(\sim 1 \mu \mathrm{m})$ long Rod-shaped $\mathrm{CCMV}_{\mathrm{TT}}$-VLPs were used.

\subsection{Rod-shaped CCMV $V_{T T}$-VLPs induce reduced switching to IgG2b/IgG2c in comparison to the Round-shaped $C C M V_{T T}-V L P S$}

The C57BL/6J murine IgG family consists of four major subclasses IgG1, IgG2b, IgG2c and IgG3. Each unique subclass is implicated in distinct effector functions during humoral immune responses. VLPs and other nanoparticles induce a humoral response dominated by IgG1 in the absence of packaged RNA or DNA in mice [29,38,39]. Isotype switching to the protective IgG2 subtype is strictly TLR dependent. Thus, VLPs packaged with prokaryotic ssRNA during $E$. coli production induce a humoral immune response dominated with IgG2 subclasses [40,41]. Based on these grounds, we were interested in characterizing the different IgG subclasses in mice sera vaccinated with Round- or Rodshaped $\mathrm{CCMV}_{\mathrm{TT}}$-VLPs, respectively. As explained earlier the engineered Round- and Rod-shaped CCMV $\mathrm{TT}_{\mathrm{TT}}$-VLPs package the same quantity of ssRNA. Therefore, TLR7/8 ligand effect can be eliminated as a confounding variable and the difference in the induced IgG subclasses can be correlated to the size of the VLPs. Our analysis revealed that Round-shaped $\mathrm{CCMV}_{\mathrm{TT}}$-VLPs significantly enhanced all IgG subclasses compared to the Rod-shaped ones. The difference, however, was most striking for TLR7/8 related subclasses IgG2b/c and IgG3 (Fig. 4a). By performing OD50 analysis we compared the titers (given as reciprocal dilution values) in both groups as depicted in Fig. $4 \mathrm{~b}$. Titers are significantly higher (p. $<0.01$ for IgG1, IgG2b and IgG2c) (p. $<0.05$ for IgG3) post immunization with Round-shaped $\mathrm{CCMV}_{\mathrm{TT}}$-VLPs. The ratio between Th1 and Th2 associated IgG subclasses was calculated next and it became evident that Th1 contribution is more pronounced with Roundshaped CCMV $\mathrm{TT}_{\text {-VLPs (Fig. 4c). }}$

\subsection{Systemic IgA response depends on size of VLPS}

Previous studies have shown that s.c. injection of VLPs packaging RNA leads to a strong serum IgA in a Th-cell independent manner [40]. In addition, our previous findings revealed that systemic IgA response is heavily dependent on TLR7/8 in B cells [42]. The role of the size of VLPs packaging similar contents of RNA has not been investigated before, therefore we carried out an experiment to investigate this matter. Our findings indicate that Round-shaped $\mathrm{CCMV}_{\mathrm{TT}}$-VLPs could induce significantly higher (p. $<0.01$ ) isotype switching to IgA when compared to the Rod-shaped ones (Fig. $5 \mathrm{a}$ and $\mathrm{b}$ ). To rule out differences in type I Th cell induction, we have also measured IFN- $\gamma$ in the serum of vaccinated mice on day 21; the results showed no significant difference (p. $>0.9999$ ) between both groups (Fig. 5c). More specifically, factoring in the LOD (limit of detection) of the INF- $\gamma$ detection kit of $4 \mathrm{ng} / \mathrm{ml}$, we conclude, that neither Round- nor Rod-shaped $\mathrm{CCMV}_{\mathrm{TT}}$-VLPs are capable of inducing strong INF- $\gamma$ responses.

\subsection{Germinal center formation is prominent following a single dose of Round-shaped $C C M V_{T T}$-VLPS}

Antigen reservoir persisting on follicular dendritic cells (fDCs) is essential for germinal centers (GC) to keep B cells stimulated and to generate a strong and long-lived antibody response. We therefore studied the formation of GCs in the spleens of mice vaccinated with Round- and Rod-shaped $\mathrm{CCMV}_{\mathrm{TT}}$-VLPs 12 days following a single s.c. dose of the engineered VLPs. Results showed that the formation of GCs in mice vaccinated with Round-shaped $\mathrm{CCMV}_{\mathrm{TT}}$-VLPs was significantly 
a.

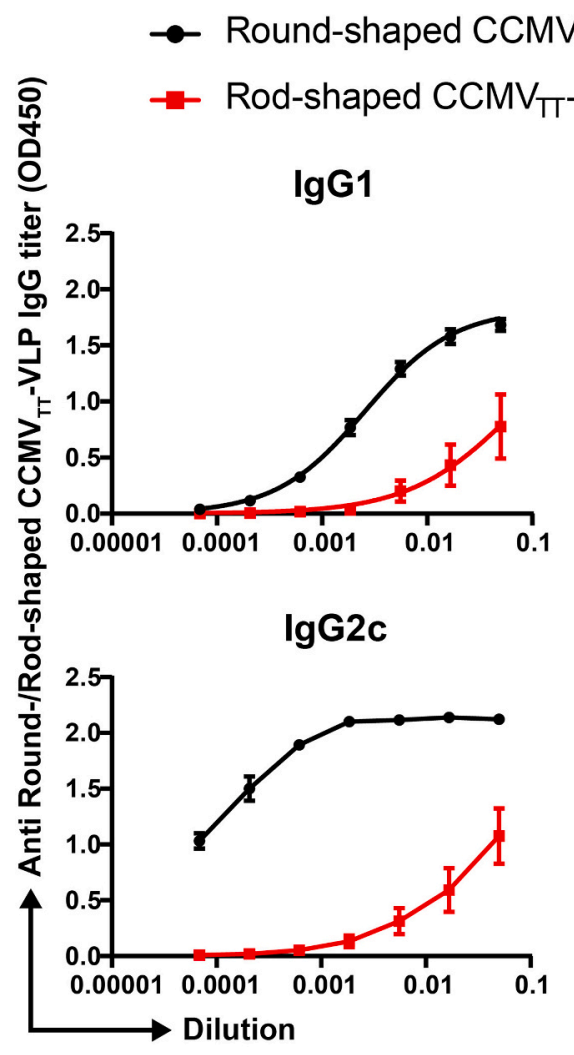

b.

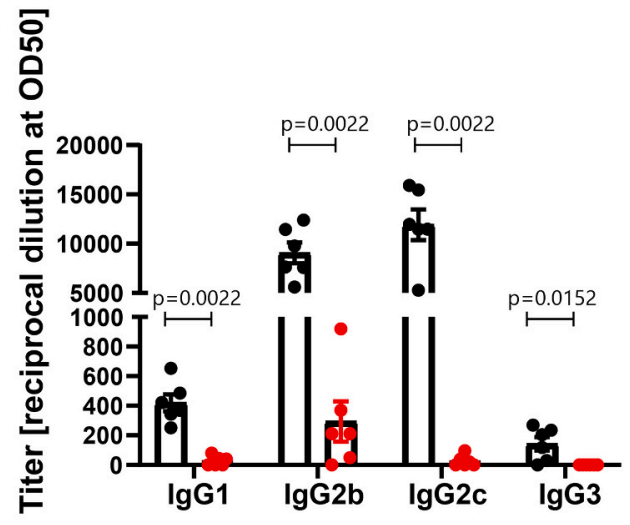

c.

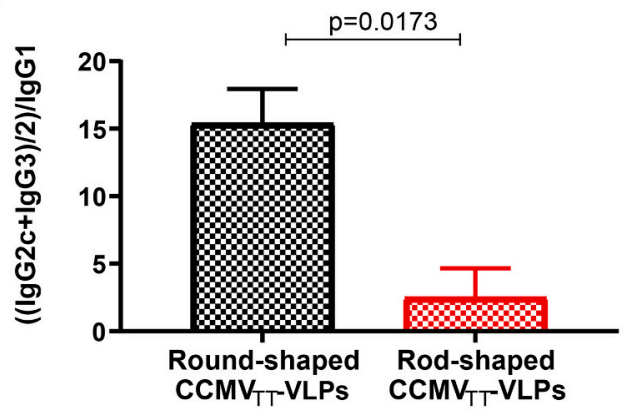

Fig. 4. Rod-shaped $C C M V_{T T}$-VLPs induce reduced switching to IgG2c/IgG2b in comparison to the Round-shaped $C C M V_{T T}$-VLPs. a, Anti-Round- and Rod-shaped CCMV $\mathrm{TT}^{-}$ VLP specific IgG1, IgG2b, IgG2c and IgG3 titers measured in day 21 mice sera using OD450nm. ELISA plates were coated with Round-shaped CCMV $\mathrm{TT}_{\mathrm{TT}} \mathrm{VLPs}_{\mathrm{L}}$ for detecting IgG subclasses in mice vaccinated with Round-shaped CCMV $\mathrm{TT}_{\mathrm{TT}}$-VLPs. ELISA plates were coated with Rod-shaped CCMV $\mathrm{TT}_{\mathrm{TT}} \mathrm{VLPs}_{\mathrm{S}}$ for detecting IgG subclasses in mice vaccinated with Rod-shaped CCMV $\mathrm{TT}_{\mathrm{TT}} \mathrm{VLPs}$. $b$, Anti-Round- and Rod-shaped CCMV $\mathrm{TT}_{\mathrm{TT}} \mathrm{VLP}$ specific IgG1, IgG2b, IgG2c and IgG3 titers measured in day 21 mice

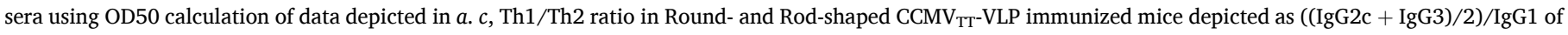
OD50 values shown in $b$. Mean \pm SEM, 6 mice per group, one representative of 2 similar experiments is shown.

a.

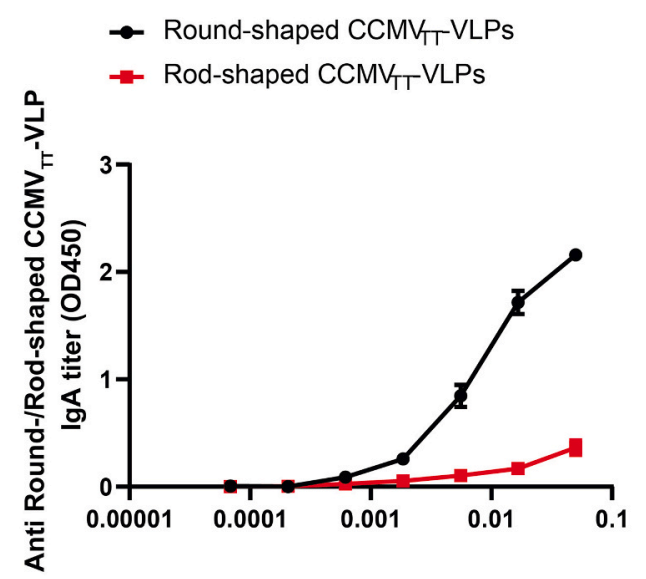

b.

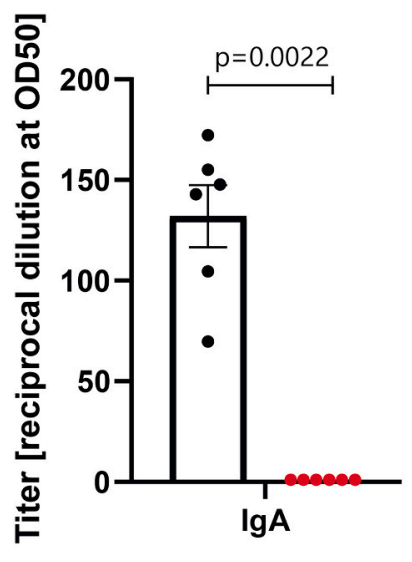

C.

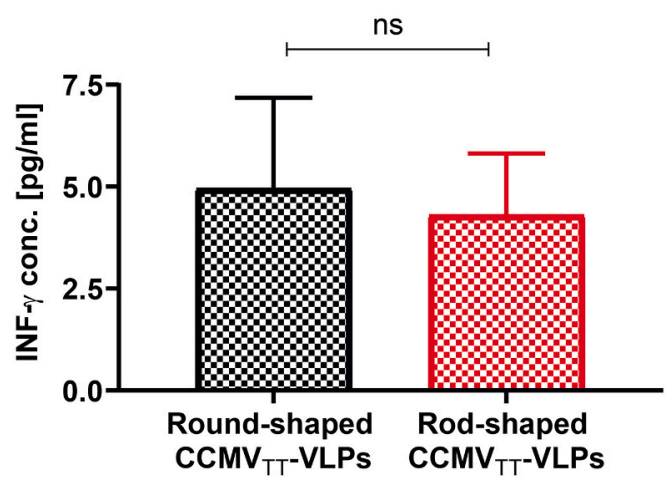

Fig. 5. Systemic IgA response depends on size of VLPs. a, Anti-Round- and Rod-shaped $\mathrm{CCMV}_{\mathrm{TT}}$-VLP specific IgA titers measured in day 35 serum from mice vaccinated with Round- and Rod-shaped $\mathrm{CCMV}_{\mathrm{TT}}$-VLPs using OD450nm. ELISA plates were coated with Round-shaped $\mathrm{CCMV}_{\mathrm{TT}}$-VLPs for detecting IgA Abs in mice vaccinated with Round-shaped $\mathrm{CCMV}_{\mathrm{TT}}$-VLPs. ELISA plates were coated with Rod-shaped $\mathrm{CCMV}_{\mathrm{TT}}$-VLPs for detecting IgA Abs in mice vaccinated with Rod-shaped CCMV $\mathrm{TT}^{-}$ VLPs. $b$, Anti-Round- and Rod-shaped CCMV $\mathrm{TT}_{\mathrm{TT}}$-VLP specific IgA titers measured in day 35 mice sera using OD50 calculations of data depicted in a. $c$, Concentration of IFN- $\gamma$ measured in day 14 serum from mice vaccinated with Round- and Rod-shaped CCMV $_{\mathrm{TT}}$-VLPs. Mean \pm SEM, 6 mice per group, one representative of 2 similar experiments is shown. 
a.

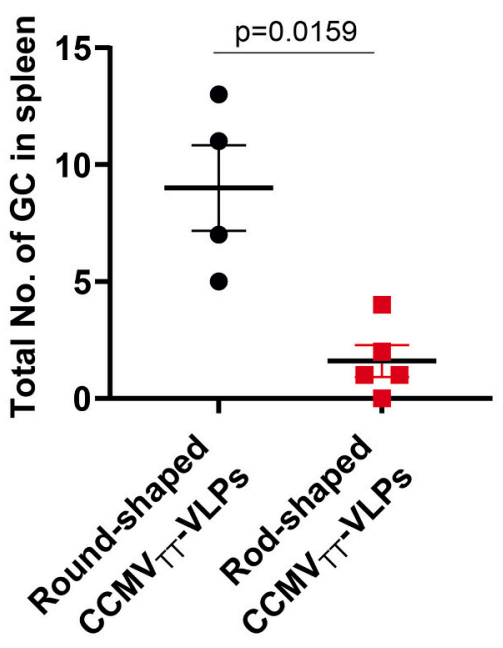

c.

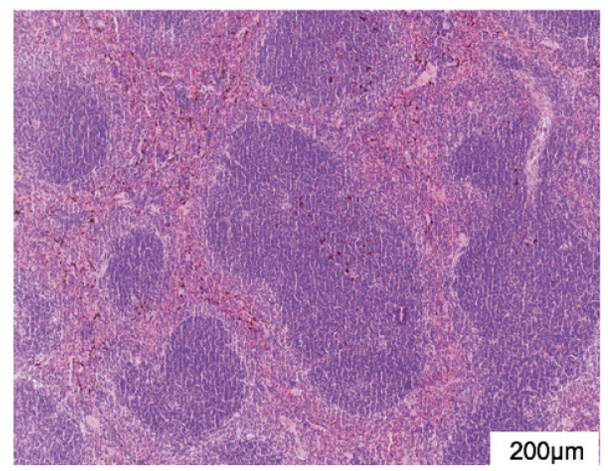

d.

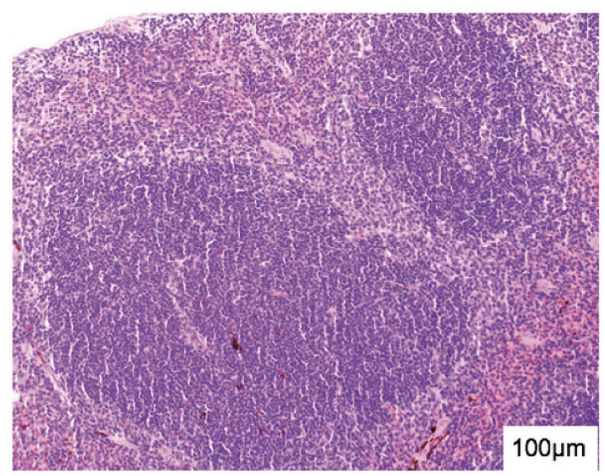

b. $\frac{5}{0}$
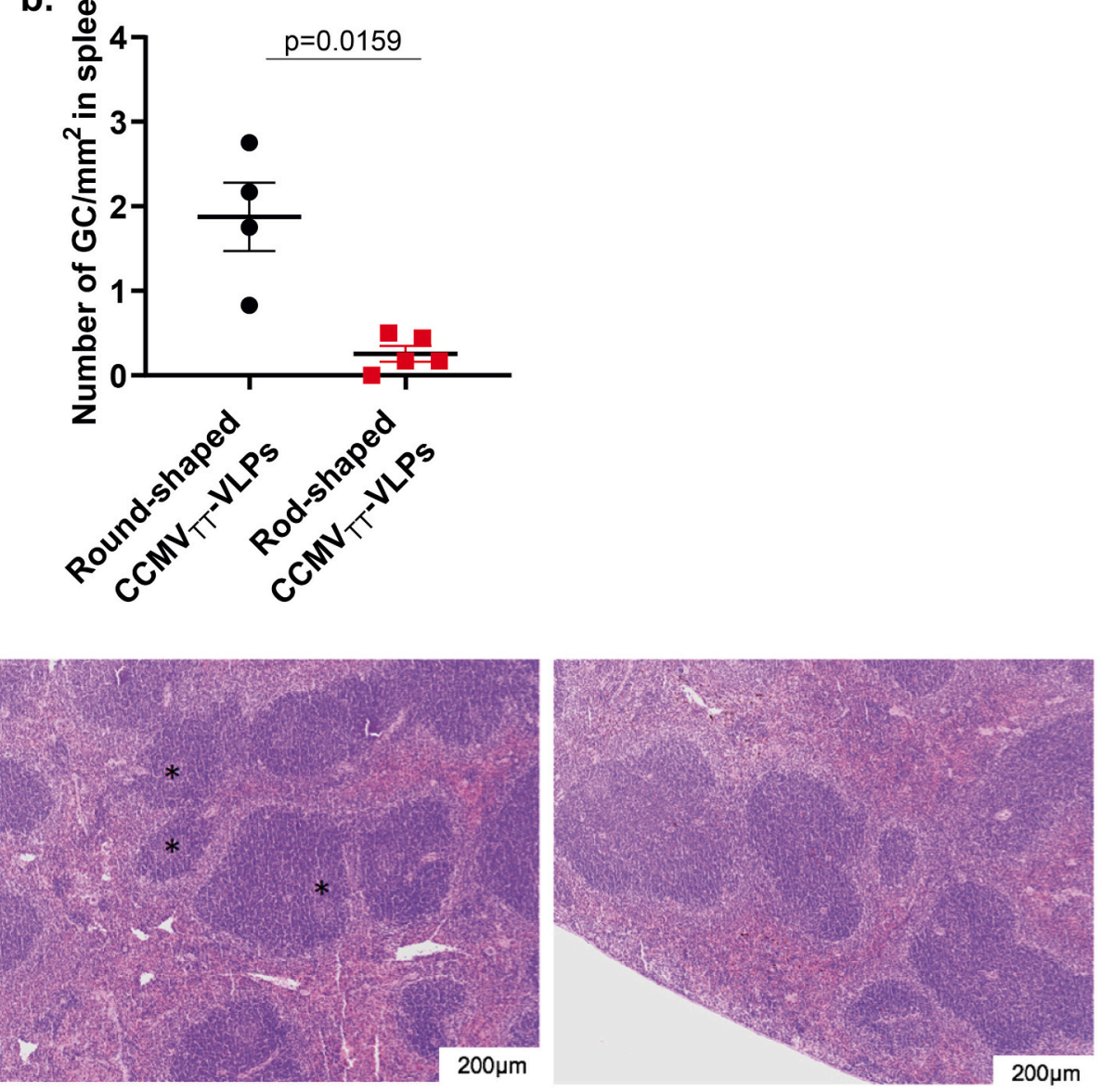

Round-shaped CCMV TT VLPS

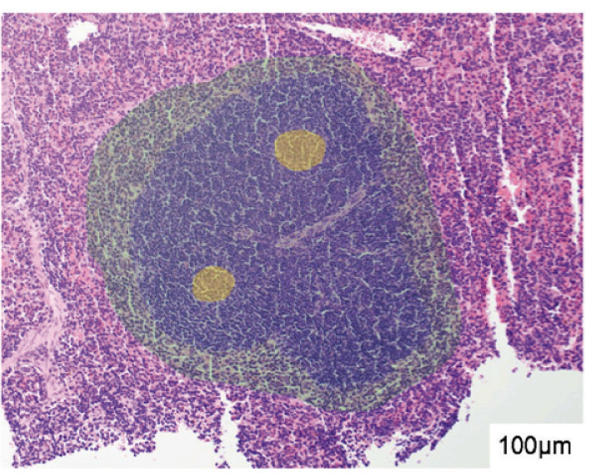

Rod-shaped CCMV TT VLPS

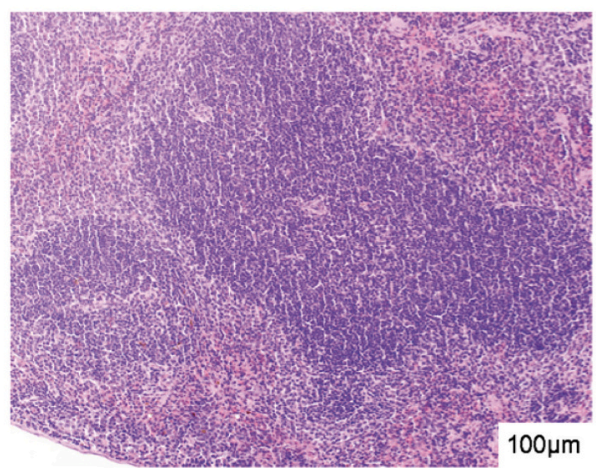

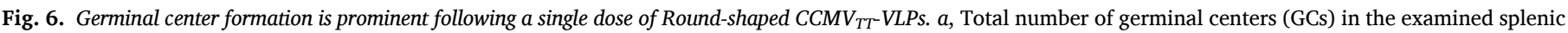

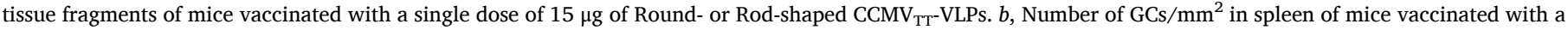

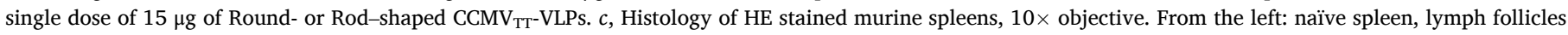

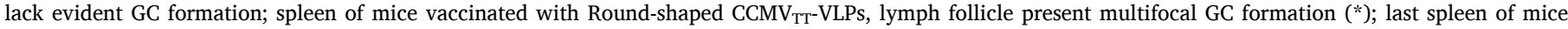

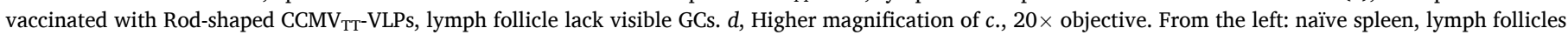

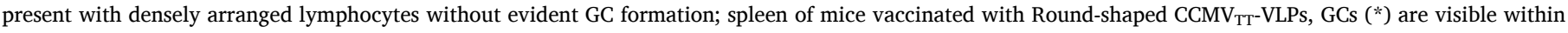

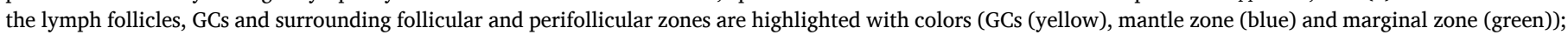

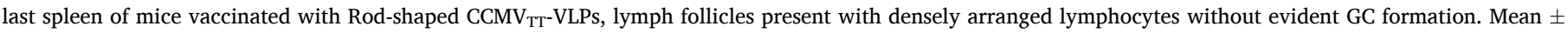

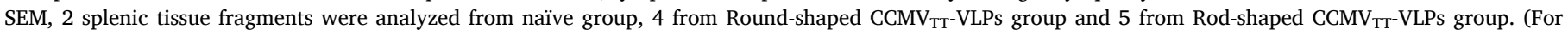
interpretation of the references to color in this figure legend, the reader is referred to the web version of this article.)

higher than in Rod-shaped $\mathrm{CCMV}_{\mathrm{TT}}$-VLP vaccinated mice when measuring the total number of GCs (p. = 0.0159) or the number of GCs/ $\mathrm{mm}^{2}$ (p. =0.0159) (Fig. 6a and b). Histological examination of Hematoxylin and Eosin (HE) stained splenic tissue indicated the presence of multiple GCs within the lymphoid follicles upon vaccination with Round-shaped $\mathrm{CCMV}_{\mathrm{TT}}$-VLPs. On the other hand, mice vaccinated with
Rod-shaped $\mathrm{CCMV}_{\mathrm{TT}}$-VLPs revealed only rare GC formation. Spleens from naïve C57BL/6J mice were used as a control (Fig. $6 \mathrm{c}$ and d). The examined spleens in mice vaccinated with Round- or Rod-shaped $\mathrm{CCMV}_{\mathrm{TT}}$-VLPs were free of any relevant degenerative or necrotic histopathological changes. 


\section{Discussion}

In the current study we have engineered VLPs with nearly identical primary sequence but fundamentally different structural properties; one forming round icosahedrons with a diameter of around $30 \mathrm{~nm}$ while the other formed rods of about $\sim 1 \mu \mathrm{m}$. To this end, we inserted a universal tetanus toxin (TT) epitope at the $\mathrm{N}$ or $\mathrm{C}$-terminus of cowpea chlorotic mottle virus (CCMV)-VLPs. The insertion of TT epitope at the N-terminus did not interfere with the original parental structure and resulted in icosahedral particles $T=3$; named in this study as Round-shaped $\mathrm{CCMV}_{\mathrm{TT}}$-VLPs. However, inserting TT epitope at the C-terminus of CCMV-VLPs caused the formation of Rod-shaped $\mathrm{CCMV}_{\mathrm{TT}}$-VLPs of $\sim 1$ $\mu \mathrm{m}$ in length and $\sim 30 \mathrm{~nm}$ in width. As both engineered VLPs were expressed in $E$. coli, they packaged a similar quantity of ssRNA serving as TLR7/8 agonists recognized by PRRs (pattern recognition receptors) for effective stimulation of the innate immune system. This allowed us to study the impact of size on drainage dynamics and the magnitude of the induced immune responses with one and the same VLP monomer while excluding the effect of TLR7/8 ligands. As mentioned above, both the surface and mass of rods are proportional to the diameter and length, allowing to vary the surface exposed to B cells with a proportional change in mass.

B cell activation by antigens is a critical step for effective initiation of the adaptive immune response [7]. Particulate antigens like VLPs can be passively or actively transported in association with e.g. dendritic cells to the lymphoid organs following injection. The passive transportation is based on their ability to drain freely through the pores of the lymphatic vessels $200 \mathrm{~nm}$ in diameter [43] as VLPs have an ideal size of $\sim 30-50$ $\mathrm{nm}$.

Our previous studies have shown that icosahedral VLPs such as bacteriophage $Q \beta$-VLPs and VLPs derived from cucumber-mosaic virus

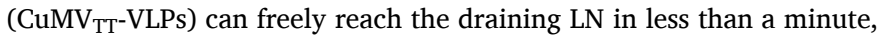
both having a size of $\sim 30 \mathrm{~nm}[9,10,44]$. By contrast, particulate antigens larger than $500 \mathrm{~nm}$ cannot efficiently enter the lymphatic capillaries $[45,46]$. Instead, they need to be actively transported via specialized cells [47]. To visualize the trafficking kinetics of the engineered Round- and Rod-shaped $\mathrm{CCMV}_{\mathrm{TT}}$-VLPs $(\sim 30 \mathrm{~nm}$ and $\sim 1 \mu \mathrm{m})$ respectively, they were labelled with AF488 and injected in mouse footpads. Flow cytometric analysis and cryosections of the popliteal LNs $3 \mathrm{~h}$ and $24 \mathrm{~h}$ post injection were performed. The results demonstrate an increase in the drainage of the Round-shaped $\mathrm{CCMV}_{\mathrm{TT}}$-VLPs $3 \mathrm{~h}$ following injection in mice footpad via the lymphatic vessels, which have pores of $\sim 200$ [43]. Nevertheless, in lower amounts Rod-shaped $\mathrm{CCMV}_{\mathrm{TT}}$-VLPs have also been detected in the draining popliteal LN $3 \mathrm{~h}$ post injection in the mouse footpad. This observation could be explained by the fact that Rod-shaped CCMV $\mathrm{TT}_{\mathrm{TT}}$-VLPs exhibit a width of $\sim 30 \mathrm{~nm}$ which might allow them to drain into the lymphatic capillaries despite their length. Indeed, if spheres of $>500 \mathrm{~nm}$ size are used for injection, these spheres required $24 \mathrm{~h}$ to arrive in LNs and fully depend on cellular transport [36].

Different subsets of cells, including APCs, interacted with Round- or Rod-shaped CCMV $\mathrm{TT}_{\text {-VLPs }}$ upon injection in mouse footpads. There was no difference in the interaction between lymphoid-derived or conventional DCs with both shapes of $\mathrm{CCMV}_{\mathrm{TT}}$-VLPs $3 \mathrm{~h}$ post injection with increased interaction of Round- compared to Rod-shaped VLPs after 24 h. Macrophages, other macrophage-derived cells as well as B cells were more efficient in interacting with Round-shaped $\mathrm{CCMV}_{\mathrm{TT}}$-VLPs compared to the Rod-shaped ones. The subcapsular sinus macrophages are considered the frontline cells to capture pathogens in the draining LN and retain them from entering the LN parenchyma. Afterwards they relay the antigen to $\mathrm{B}$ cells for efficient priming and induction of humoral immune responses [48]. Yolanda et al. proposed a model for particulate-antigen acquisition by B cells. The model suggests that particulate antigens firstly accumulate in the macrophage-niche area in the SCS of the draining LN followed by a still unknown filtration process of the antigens to the follicle. Next, non-antigen specific B cells carry particles via binding of antigens to complement receptor from the SCS to be deposited on follicular dendritic cells (FDCs) [44]. Our fluorescent microscopy cryosections could demonstrate such findings as Roundshaped $\mathrm{CCMV}_{\mathrm{TT}}$-VLPs were more efficient in draining to the popliteal LNs $3 \mathrm{~h}$ post injection in the mouse footpad where macrophages could also be abundantly observed. $24 \mathrm{~h}$ later the Round-shaped $\mathrm{CCMV}_{\mathrm{TT}}$-VLPs could be detected deeper in the LN. The interaction of the Round-shaped $\mathrm{CCMV}_{\mathrm{TT}}$-VLPs with $\mathrm{B}$ cells with increased MHC-II expression was significantly higher $(\mathrm{p} .=0.0286)$ when compared to the Rod-shaped $\mathrm{CCMV}_{\mathrm{TT}}$-VLPs, both at $3 \mathrm{~h}$ and $24 \mathrm{~h}$ post injection in the footpad as shown using FACS analysis. This is consistent with our previous observation that Round-shaped VLPs bind to B cells in a complement and CD21-dependent manner [49] and may suggest an impaired ability of B cells to bind Rod-shaped CCMV $\mathrm{TT}_{\mathrm{T}}$-VLPs.

The repetitive surface geometry of VLPs enhance their cross-linking to $B$ cells and ability to activate complement [7]. $T=3$ VLPs are capable of cross-linking up to 180 BCRs resulting in a strong humoral immune response. $T=3$ VLPs may be favorable over $T=1$ as the later can crosslink maximally $\sim 60$ BCRs which is at the threshold for an optimal immune response [50]. However, data are scarce regarding Rod-shaped VLPs and their ability to activate B cells. In this study, we show that a single priming injection of Round-shaped $\mathrm{CCMV}_{\mathrm{TT}}$-VLPs was efficient at inducing a high specific $\mathrm{Ab}$ titer which was further enhanced upon boosting on day 14. On the contrary, the Rod-shaped $\mathrm{CCMV}_{\mathrm{TT}}$-VLPs could only induce a specific $\mathrm{Ab}$ response following boosting on day 14 which remained much reduced compared to the Round-shaped VLP induced response. These results were confirmed by the significantly increased formation of total no. of GCs (p. $=0.0159$ ) as well as no. of $\mathrm{GCs} / \mathrm{mm}^{2}$ (p. $=0.0159$ ) in spleens 12 days following vaccination with Round-shaped CCMV $\mathrm{TT}_{\mathrm{TT}}$-VLPs.

When testing the sera from vaccinated mice against the opposite engineered VLPs, Round-shaped $\mathrm{CCMV}_{\mathrm{TT}}$-VLPs were also more efficient in inducing IgG antibodies recognizing the Rod-shaped VLPs even after a single dose. These data indicate that icosahedral VLPs are capable of inducing specific Ab directed against other forms of the same VLPs in an efficient manner and that $30 \mathrm{~nm}$ sized round VLPs are far superior over $1 \mu \mathrm{m}$ sized rods.

To achieve successful IgG class-switching and memory formation in B cells, co-delivery of innate immune stimuli is crucial [21]. It has been shown that class-switching to $\operatorname{IgG} 2 \mathrm{a} / \mathrm{c}$ and IgG2b is dependent on simultaneous engagement of BCR and TLR9 after immunization with particulate antigens [51,52]. Furthermore, TLR7 engagement with different RNA types influenced the outcome of the humoral immune response to VLP immunization. Bacterial RNA pointed the immune response toward IgG2 production, whereas eukaryotic RNA induced responses favored higher IgG1 titers [53]. IgG1 is associated with Th2 responses, whereas IgG2a/c and IgG3 is associated with Th1 responses even though TLR-signaling in B cells is key for IgG subclass induction. The obtained data reveal that Round-shaped $\mathrm{CCMV}_{\mathrm{TT}}$-VLPs were more efficient than the Rod-shaped VLPs at inducing class-switching. Furthermore, the ratio between Th1 and Th2 associated IgG subclasses was more significantly increased $(\mathrm{p} .=0.0173$ ) when vaccinating with Round-shaped CCMV $\mathrm{TT}_{\mathrm{TT}}$-VLPs. As class switching to IgG2a/b as well as IgA is driven by TLR7/8 signaling in B cells, these results suggest that it is easier for B cells to interact with and process particles of $\sim 30 \mathrm{~nm}$ size rather than micron-sized structures.

Similar to IgG2a responses, VLPs packaged with RNA lead to a strong systemic IgA response. We have shown previously that serum IgA responses are Th cell independent [40] and require TLR7/8 or 9 to induce a systemic response [42]. Here, we show that the systemic IgA response measured on day 21 using a s.c. prime-boost regimen was much higher in mice vaccinated with Round-shaped $\mathrm{CCMV}_{\mathrm{TT}}-\mathrm{VLPs}$ than in mice vaccinated with Rod-shaped $\mathrm{CCMV}_{\mathrm{TT}}$-VLPs $(\mathrm{p} .=0.0022$ ).

It has previously been shown that particle-drainage trafficking into $\mathrm{B}$ cell and $\mathrm{T}$ cell areas of the lymph node is heavily dependent on the size of the particles. Indeed, particles smaller $200 \mathrm{~nm}$ usually freely enter the 
lymphatic system via fenestrated lymph vessels while larger particles need to be transported by e.g. dendritic cells. This results in small particles reaching subcapsular sinuses within minutes while larger particles $(>200 \mathrm{~nm}$ ) typically reach lymph nodes after $24 \mathrm{~h}$ and mainly reach $\mathrm{T}$ cell zones as this is the region dendritic cells typically target. Despite the clearness of these results a direct impact on B cell responses has been difficult to assess; mainly because B cells respond to antigens on surfaces and the surface of the particle grows proportionally to the square of the radius $\left(r^{2}\right)$ while volume/weight is proportional to $r^{3}$. Hence, to compare particles with 10 -fold different radius, 10 -fold increased dose (weight) of the larger particle must be injected for compensation of differences in the surface. Consequently, direct comparison of B cell responses induced by small and large particles becomes impossible. This is, however, a very important point, as adjuvant may vary in size between nanometers and micrometers. In the current study, we used rods versus icosahedra built up by essentially the same monomer. As both the surface and the weight of rods is proportional to the length of the rod, B cell responses by Rodand Round-shaped VLPs are more directly comparable. We find that Round-shaped VLPs are more immunogenic for B cells by orders of magnitude, high-lighting that VLPs of a size smaller than $200 \mathrm{~nm}$ are optimal for induction of $B$ cell responses. In a next study, we will address the importance of rod size on B cell receptor and TLR7/8 stimulation and will also determine whether rods of homogenously small size are equally immunogenic as round VLPs.

\section{Authors' contributions}

Design of experiments, acquisition of data, interpretation of data and analysis of data: SZ, AO, SdB, CL, XC, MFB and MOM; VLP design, expression and production: $\mathrm{AO}, \mathrm{IB}, \mathrm{GR}$ and $\mathrm{AZ}$; H\&E stains and IF microscopy: SdB, CL, XC; Writing and revision of manuscript: SZ, MOM, AO, MFB, MV and AZ; Technical and material support: LZ, Study supervision: MOM and MFB. All authors read and approved the final manuscript.

\section{Declaration of Competing Interest}

The authors declare no competing interests

\section{Acknowledgment}

This work was supported by Qatar National Research Fund (PDRA40118-18002), the Swiss National Science Foundation (SNF 310030_185114 and SNF 310030_179165) and by Latvian Science Council (Grant No. lzp-2019/1-0131).

\section{Appendix A. Supplementary data}

Supplementary data to this article can be found online at https://doi. org/10.1016/j.jconrel.2021.01.012.

\section{References}

[1] F.H. Crick, J.D. Watson, Structure of small viruses, Nature 177 (4506) (Mar 10 1956) 473-475, https://doi.org/10.1038/177473a0.

[2] D.L. Caspar, Movement and self-control in protein assemblies. Quasi-equivalence revisited, Biophys. J. 32 (1) (Oct 1980) 103-138, https://doi.org/10.1016/S00063495(80)84929-0.

[3] J. Louten, Essential Human Virology, 2017, p. 344.

[4] A.C. Gomes, M. Mohsen, M.F. Bachmann, Harnessing Nanoparticles for Immunomodulation and Vaccines, Vaccines (Basel) 5 (1) (Feb 14 2017), https:// doi.org/10.3390/vaccines5010006.

[5] M.O. Mohsen, A.C. Gomes, M. Vogel, M.F. Bachmann, Interaction of Viral CapsidDerived Virus-Like Particles (VLPs) with the Innate Immune System, Vaccines (Basel) 6 (3) (Jul 2 2018), https://doi.org/10.3390/vaccines6030037.

[6] M.F. Bachmann, U.H. Rohrer, T.M. Kundig, K. Burki, H. Hengartner, R. M. Zinkernagel, The influence of antigen organization on B cell responsiveness, Science 262 (5138) (Nov 26 1993) 1448-1451, https://doi.org/10.1126/ science. 8248784 .
[7] M.F. Bachmann, G.T. Jennings, Vaccine delivery: a matter of size, geometry, kinetics and molecular patterns, Nat Rev Immunol 10 (11) (Nov 2010) 787-796, https://doi.org/10.1038/nri2868.

[8] J.E. Gretz, C.C. Norbury, A.O. Anderson, A.E. Proudfoot, S. Shaw, Lymph-borne chemokines and other low molecular weight molecules reach high endothelial venules via specialized conduits while a functional barrier limits access to the lymphocyte microenvironments in lymph node cortex, J Exp Med 192 (10) (Nov 20 2000) 1425-1440, https://doi.org/10.1084/jem.192.10.1425.

[9] M.O. Mohsen, et al., Delivering adjuvants and antigens in separate nanoparticles eliminates the need of physical linkage for effective vaccination, J. Control. Release 251 (Apr 10 2017) 92-100, https://doi.org/10.1016/j.jconrel.2017.02.031.

[10] M.O. Mohsen, et al., Correction to: Vaccination with nanoparticles combined with micro-adjuvants protects against cancer, J Immunother Cancer 7 (1) (May 23 2019) 137, https://doi.org/10.1186/s40425-019-0616-y.

[11] D.L. Caspar, A. Klug, Physical principles in the construction of regular viruses, Cold Spring Harb. Symp. Quant. Biol. 27 (1962) 1-24, https://doi.org/10.1101/ sqb.1962.027.001.005.

[12] M.O. Mohsen, G. Augusto, M.F. Bachmann, The 3Ds in virus-like particle basedvaccines: "Design, Delivery and Dynamics", Immunol Rev (May 30) (2020) https:// doi.org/10.1111/imr.12863.

[13] J.W. Wang, R.B. Roden, Virus-like particles for the prevention of human papillomavirus-associated malignancies, Expert Rev Vaccines 12 (2) (Feb 2013) 129-141, https://doi.org/10.1586/erv.12.151.

[14] T.S. Guu, et al., Structure of the hepatitis E virus-like particle suggests mechanisms for virus assembly and receptor binding (in eng), Proc Natl Acad Sci U S A 106 (31) (Aug 4 2009) 12992-12997, https://doi.org/10.1073/pnas.0904848106.

[15] J.K. Ho, B. Jeevan-Raj, H.J. Netter, Hepatitis B Virus (HBV) Subviral Particles as Protective Vaccines and Vaccine Platforms (in eng), Viruses 12 (2) (Jan 21 2020), https://doi.org/10.3390/v12020126.

[16] M.L. Chapman, Advances in Protein Chemistry, 2003, pp. 1-253.

[17] P. Ge, Z.H. Zhou, Hydrogen-bonding networks and RNA bases revealed by cryo electron microscopy suggest a triggering mechanism for calcium switches, Proceedings of the National Academy of Sciences 108 (23) (2011) 9637, https:// doi.org/10.1073/pnas.1018104108.

[18] Y. Zhang, Y.X. Dong, J.H. Zhou, X. Li, F. Wang, Application of Plant Viruses as a Biotemplate for Nanomaterial Fabrication (in English), Molecules 23 (9) (Sep 2018), https://doi.org/10.3390/molecules23092311. doi: ARTN 2311.

[19] I. Balke, A. Zeltins, Recent Advances in the Use of Plant Virus-Like Particles as Vaccines (in English), Viruses-Basel 12 (3) (Mar 2020), https://doi.org/10.3390/ v12030270. doi: ARTN 270.

[20] I. Cielens, et al., Mutilation of RNA phage Qbeta virus-like particles: from icosahedrons to rods, FEBS Lett 482 (3) (Oct 6 2000) 261-264, https://doi.org/ 10.1016/s0014-5793(00)02061-5.

[21] G.T. Jennings, M.F. Bachmann, The coming of age of virus-like particle vaccines in: Biological Chemistry Volume 389 Issue 5 (2008), in: Biological Chemistry, Volume 389: Issue 5, ed, 2008.

[22] G.T. Jennings, M.F. Bachmann, Immunodrugs: Therapeutic VLP-Based Vaccines for Chronic Diseases, in: Annual Review of Pharmacology and Toxicology vol. 49, 2009, pp. 303-326, ed: Annual Reviews.

[23] G. Cabral-Miranda, et al., Zika Virus-Derived E-DIII Protein Displayed on Immunologically Optimized VLPs Induces Neutralizing Antibodies without Causing Enhancement of Dengue Virus Infection, Vaccines (Basel) 7 (3) (Jul 23 2019), https://doi.org/10.3390/vaccines7030072.

[24] F. Olomski, et al., Interleukin 31 in insect bite hypersensitivity-alleviating clinical symptoms by active vaccination against itch, Allergy 75 (4) (Apr 2020) 862-871, https://doi.org/10.1111/all.14145.

[25] A. Fettelschoss-Gabriel, et al., Active vaccination against interleukin-5 as long-term treatment for insect-bite hypersensitivity in horses, Allergy 74 (3) (Mar 2019) 572-582, https://doi.org/10.1111/all.13659.

[26] F. Thoms, et al., Immunization of cats to induce neutralizing antibodies against Fel $\mathrm{d} 1$, the major feline allergen in human subjects, J. Allergy Clin. Immunol. 144 (1) (Jul 2019) 193-203, https://doi.org/10.1016/j.jaci.2019.01.050.

[27] F. Storni, et al., Vaccine against peanut allergy based on engineered virus-like particles displaying single major peanut allergens, J Allergy Clin Immunol 145 (4) (Apr 2020), https://doi.org/10.1016/j.jaci.2019.12.007, 1240-1253 e3.

[28] G. Cabral-Miranda, et al., DOPS Adjuvant Confers Enhanced Protection against Malaria for VLP-TRAP Based Vaccines (in eng), Diseases (Basel, Switzerland) 6 (4) (2018) 107, https://doi.org/10.3390/diseases6040107.

[29] G.P. Pogue, J.A. Lindbo, S.J. Garger, W.P. Fitzmaurice, Making an ally from an enemy: plant virology and the new agriculture, Annu. Rev. Phytopathol. 40 (2002) 45-74, https://doi.org/10.1146/annurev.phyto.40.021102.150133.

[30] M.L. Smith, et al., Modified tobacco mosaic virus particles as scaffolds for display of protein antigens for vaccine applications, Virology 348 (2) (May 102006 ) 475-488, https://doi.org/10.1016/j.virol.2005.12.039.

[31] A. Hassani-Mehraban, S. Creutzburg, L. van Heereveld, R. Kormelink, Feasibility of Cowpea chlorotic mottle virus-like particles as scaffold for epitope presentations (in English), Bmc Biotechnol 15 (Aug 27 2015), https://doi.org/10.1186/s12896015-0180-6. doi: ARTN 80.

[32] J.A. Speir, S. Munshi, G. Wang, T.S. Baker, J.E. Johnson, Structures of the native and swollen forms of cowpea chlorotic mottle virus determined by X-ray crystallography and cryo-electron microscopy, Structure 3 (1995) 63-78, ed.

[33] K.W. Adolph, P.J. Butler, Studies on the assembly of a spherical plant virus. I. States of aggregation of the isolated protein (in eng), Journal of molecular biology 88 (2) (Sep 15 1974) 327-341, https://doi.org/10.1016/0022-2836(74)90485-9.

[34] A. Zeltins, et al., Incorporation of tetanus-epitope into virus-like particles achieves vaccine responses even in older recipients in models of psoriasis, Alzheimer's and 
cat allergy, NPJ Vaccines 2 (2017) 30, https://doi.org/10.1038/s41541-017-00308.

[35] J.M. Fox, X. Zhao, J.A. Speir, M.J. Young, Analysis of a salt stable mutant of cowpea chlorotic mottle virus, in: Virology vol. 222, ed: Academic Press Inc, 1996, pp. 115-122.

[36] V. Manolova, A. Flace, M. Bauer, K. Schwarz, P. Saudan, M.F. Bachmann, Nanoparticles target distinct dendritic cell populations according to their size (in English), European Journal of Immunology 38 (5) (May 2008) 1404-1413, https:// doi.org/10.1002/eji.200737984.

[37] L. Kahari, et al., Transcytosis route mediates rapid delivery of intact antibodies to draining lymph nodes, J Clin Invest 129 (8) (Jun 24 2019) 3086-3102, https://doi. org/10.1172/JCI125740.

[38] G.T. Jennings, M.F. Bachmann, The coming of age of virus-like particle vaccines, Biol. Chem. 389 (5) (May 2008) 521-536, https://doi.org/10.1515/bc.2008.064.

[39] C. G. A, E.S. Roesti, A. El-Turabi, M.F. Bachmann, Type of RNA Packed in VLPs Impacts IgG Class Switching-Implications for an Influenza Vaccine Design, Vaccines (Basel) 7 (2) (Jun 4 2019), https://doi.org/10.3390/vaccines7020047.

[40] J. Bessa, M.F. Bachmann, T cell-dependent and -independent IgA responses: role of TLR signalling, Immunol. Investig. 39 (4-5) (2010) 407-428, https://doi.org/ 10.3109/08820131003663357.

[41] A. Jegerlehner, P. Maurer, J. Bessa, H.J. Hinton, M. Kopf, M.F. Bachmann, TLR9 signaling in B cells determines class switch recombination to IgG2a, J Immunol 178 (4) (Feb 15 2007) 2415-2420, https://doi.org/10.4049/jimmunol.178.4.2415.

[42] J. Bessa, et al., Alveolar macrophages and lung dendritic cells sense RNA and drive mucosal IgA responses, J Immunol 183 (6) (Sep 15 2009) 3788-3799, https://doi org/10.4049/jimmunol.0804004.

[43] Y.A.P.P. Khudyakov, viral nanotechnology, Taylor and Francis Group LLC, 2016.

[44] Y.R. Carrasco, F.D. Batista, B cells acquire particulate antigen in a macrophage-rich area at the boundary between the follicle and the subcapsular sinus of the lymph node, Immunity 27 (1) (Jul 2007) 160-171, https://doi.org/10.1016/j. immuni.2007.06.007.
[45] S.T. Reddy, et al., Exploiting lymphatic transport and complement activation in nanoparticle vaccines, Nat. Biotechnol. 25 (10) (Oct 2007) 1159-1164, https:// doi.org/10.1038/nbt1332.

[46] D.A. Berk, M.A. Swartz, A.J. Leu, R.K. Jain, Transport in lymphatic capillaries. II. Microscopic velocity measurement with fluorescence photobleaching, Am. J. Phys. 270 (1 Pt 2) (Jan 1996) H330-H337, https://doi.org/10.1152/ ajpheart.1996.270.1.H330.

[47] V. Manolova, A. Flace, M. Bauer, K. Schwarz, P. Saudan, M.F. Bachmann, Nanoparticles target distinct dendritic cell populations according to their size, Eur. J. Immunol. 38 (5) (May 2008) 1404-1413, https://doi.org/10.1002/ eji.200737984.

[48] D.A.P. Louie, S. Liao, Lymph Node Subcapsular Sinus Macrophages as the Frontline of Lymphatic Immune Defense (in English), Frontiers in Immunology 10 (Feb 28 2019), https://doi.org/10.3389/fimmu.2019.00347. doi: ARTN 347.

[49] M.O. Mohsen, D.E. Speiser, A. Knuth, M.F. Bachmann, Virus-like particles for vaccination against cancer, Wiley Interdiscip Rev Nanomed Nanobiotechnol 12 (1) (Jan 2020) e1579, https://doi.org/10.1002/wnan.1579.

[50] A. Jegerlehner, T. Storni, G. Lipowsky, M. Schmid, P. Pumpens, M.F. Bachmann, Regulation of IgG antibody responses by epitope density and CD21-mediated costimulation, Eur. J. Immunol. 32 (11) (Nov 2002) 3305-3314, https://doi.org/ 10.1002/1521-4141(200211)32:11<3305::AID-IMMU3305>3.0.CO;2-J.

[51] J. Eckl-Dorna, F.D. Batista, BCR-mediated uptake of antigen linked to TLR9 ligand stimulates B-cell proliferation and antigen-specific plasma cell formation, Blood 113 (17) (Apr 23 2009) 3969-3977, https://doi.org/10.1182/blood-2008-10185421.

[52] B. Hou, et al., Selective utilization of toll-like receptor and Myd88 signaling in B cells for enhancement of the antiviral germinal center response, in: Immunity vol. 34, 2011, pp. 375-384, ed: NIH Public Access.

[53] A.C. Gomes, E.S. Roesti, A. El-Turabi, M.F. Bachmann, Type of RNA packed in VLPs impacts IgG class switching-implications for an influenza vaccine design, in: Vaccines vol. 7, 2019 ed: MDPI AG. 